Working Paper 02-08

Business Economics Series 03

March 2002
Departamento de Economía de la Empresa

Universidad Carlos III de Madrid

Calle Madrid, 126

28903 Getafe (Spain)

Fax (34-91) 6249608

\title{
EMPLOYER BEHAVIOR WHEN WORKERS CAN UNIONIZE
}

\author{
Pablo Ruiz Verdú*
}

Abstract

Unionization imposes substantial costs on employers. This paper develops a model that recognizes that, as a result, employers will set wages and employment taking into account the effect of their decisions on workers' incentives to organize. This model of employer behavior allows us to address two questions jointly: What determines which firms become unionized? And what are the consequences of unionization for employment and wages in nonunion firms? The implications of the model depart significantly from those of previous work, which either ignored employers' strategic behavior, or treated these questions in isolation.

Keywords: Employment determination, Wage determination, Unionization, Union threat, Wage differentials

JEL-Codes: J51, J23, J31, J41, D82, M50.

"Universidad Carlos III. Department of Business Administration. C/ Madrid, 126. 28903 Getafe (Madrid, Spain). E-mail: prverdu@emp.uc3m.es 


\title{
Employer Behavior When Workers Can Unionize*
}

\author{
Pablo Ruiz-Verdú ${ }^{\dagger}$
}

March 4, 2002.

\begin{abstract}
Unionization imposes substantial costs on employers. This paper develops a model that recognizes that, as a result, employers will set wages and employment taking into account the effect of their decisions on workers' incentives to organize. This model of employer behavior allows us to address two questions jointly: What determines which firms become unionized? And what are the consequences of unionization for employment and wages in nonunion firms? The implications of the model depart significantly from those of previous work, which either ignored employers' strategic behavior, or treated these questions in isolation. JEL: J23, J31, J51, J41, M50, D82. Keywords: employment determination, wage determination, unions, wage differentials.
\end{abstract}

*This paper is based on my Ph.D. dissertation "Labor Markets under Endogenous Union Formation". Financial support by the John M. Olin Foundation through a grant to the Stanford Institute for Economic Policy Research, and from the Bank of Spain for earlier stages of this research, is gratefully acknowledged. I have benefited greatly from the suggestions of my dissertation advisors John Pencavel, Edward Lazear, and Steve Tadelis. I thank Robert Flanagan, Luigi Pistaferri, Robert McMillan, Davide Lombardo, Giovanni Facchini, Clemens Sialm, Ravi Singh, Ayako Yasuda, and seminar participants at Stanford University for their helpful comments. Of course, any remaining errors are mine.

${ }^{\dagger}$ Address: Universidad Carlos III de Madrid, Department of Business Administration. Calle Madrid, 126 28903 - Getafe, Madrid - Spain. E-mail: prverdu@emp.uc3m.es. 


\section{Introduction}

Unionization is very costly to employers. Despite the dramatic decline in the rate of union membership in the U.S. over the past twenty years, the wage premium that unions guarantee their members is substantial - between 15 and 25 percent - and has not shown any significant downward trend (see Figure $1^{1}$ ). Therefore, unless unionization has a large positive effect on productivity, firms have powerful incentives to remain nonunion. As has been well documented, if employers perceive any risk of unionization, they adjust their wage and employment policies to make joining a union less attractive to workers (Rees and Schultz (1970), Foulkes (1980)), and, if that fails, resist union organization strongly, even if this frequently involves taking legally questionable actions (Freeman (1986), Freeman and Kleiner (1990)). ${ }^{2}$

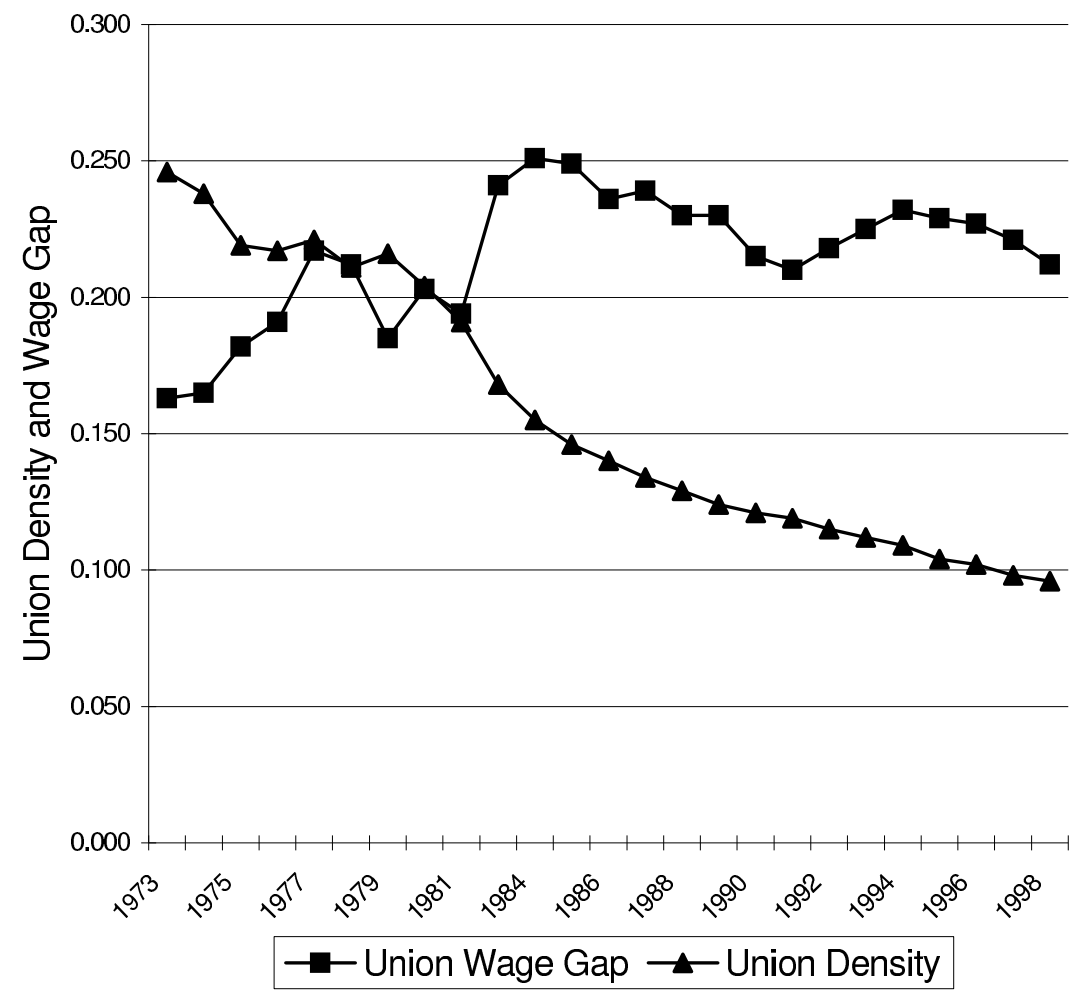

Figure 1: Union-nonunion Wage Gap and Union Density among Private Sector Nonagricultural Workers. 1973-1998. (Source: Hirsch and Schumacher (2000))

Thus when faced with potential unionization, employers take into account the effect of their decisions on workers' incentives to unionize. This means that, on the one hand, employers'

\footnotetext{
${ }^{1}$ Figure 1 plots union density and the union wage gap for private sector, nonagricultural workers in the U.S. for the period 1973-1981,1983-1998. The wage differentials are calculated in Hirsch and Schumacher (2000) from CPS data, excluding workers with earnings imputed by the Census. See Hirsch and Schumacher (2000) for a discussion of the dataset, the controls used in the wage equations, and the reasons to exclude allocated earners.

${ }^{2}$ In 1994, the ratio of unfair labor practice complaints issued by the National Labor Relations Board (NLRB) to the number of union recognition elections was 0.843 (Ehrenberg and Smith (1997), p. 493). See also Flanagan (1989).
} 
wage and employment choices under the threat of unionization will differ from those they would make in the absence of such threat, and that, on the other hand, unionization cannot be analyzed independently of wage determination. The contribution of this paper is to develop a model in which nonunion employers behave strategically, and in which wages, employment, and the incidence of unionization are simultaneously determined. The model shows that, once we account for this simultaneity, we obtain predictions both about the effects of the threat of collective bargaining on employment and wages, and about the determinants of unionization that depart significantly from the received wisdom.

There are two main views as to the effect of unions on the wages and employment of nonunion workers. ${ }^{3}$ According to the first of these views (the crowding or spillover view), the nonunion sector behaves competitively, and therefore the impact of unionization on the wages and employment of nonunion workers takes place solely through its effect on the supply of labor to the nonunion sector. If, as commonly assumed, collective bargaining reduces employment in the union sector, it follows that unionization lowers wages in the nonunion sector, as the latter absorbs the displaced workers.

The union threat view, in contrast, holds that nonunion employers raise wages to forestall unionization (Rosen (1969)), and, as a consequence cut employment as they move up their labor demand curves. Since wages are prevented from falling by the union threat, the labor market does not clear, and unemployment ensues.

With respect to the determinants of the incidence of unionization, it is often argued that those firms where the expected wage gains from unionization are larger are more likely to become unionized. In turn, these wage gains are expected to be larger in those firms earning higher rents, so unionization should be more likely in more profitable firms (see, for example, Hirsch (1991), p. 60). To the extent that changes in estimated union wage premia reflect changes in the expected wage gains from unionization, union membership and the union wage premium should be positively correlated. This argument has led some researchers (e.g. Blanchflower (1997)) to consider it a puzzle that despite the precipitous decline in U.S. (and British) union density in the last two decades, union wage premia have remained unaltered. One proposed explanation for this apparent puzzle has been that the high union wage differentials of the late 1970s were precisely the cause of the decline in union density: High wage differentials would have led employers to resist organization more strongly, a change recorded by the increase in the number of unfair labor practice complaints. ${ }^{4}$ However, this story does not explain what prompted the initial shift to higher wage differentials, and why, after the long decline in union density, wage differentials have remained high rather than return to their initial values. (Again, see Figure 1.) The absence of a model that simultaneously explains wage determination and unionization (the only exception being Lazear (1983)) means that there is no theoretical account

\footnotetext{
${ }^{3}$ See Ehrenberg and Smith (1997) for a standard textbook exposition of these two views.

${ }^{4}$ See Freeman and Medoff (1984), Freeman (1986), Freeman and Kleiner (1990), Blanchflower and Freeman (1992), Blanchflower (1997).
} 
of these trends.

Whether more profitable firms are more likely to become organized is an interesting question in its own right, but it may be even more relevant because of its consequences for the estimation of the effects of unionization. One of the main problems in the empirical literature examining the effects of unions is that unionization is likely to be correlated with unobservable firm characteristics that also influence the variable of interest (be it profits, wages, etc.). For example, suppose that we were interested in estimating the effect of unionization on profits, and unionization was more likely to occur in more profitable firms. Then, unless we can perfectly control for expected profitability, OLS estimates of the union effect on profits would tend to be downward-biased, that is, they would show a smaller -in absolute value- negative effect. Similarly, estimates of the union wage premium would tend to overestimate the true effect of unions on compensation.

In contrast to these views, the model in this paper shows that: (1) The threat of unionization induces nonunion employers to increase their wages above competitive levels, but does not generally reduce employment as a consequence. (2) Only the presence of asymmetric information about firm profitability may lead worse performing firms to reduce employment to convince workers that they cannot expect high wage gains if they organize. (3) Firms earning lower rents are more likely to become unionized. (4) Negative industry shocks make unionization more likely. (5) Conventional estimates of the effect of unions on profits will be upward biased, while estimates of the union wage premium may be downward biased. (6) In equilibrium, union membership and the union wage premium will tend to be negatively correlated.

These predictions follow from the recognition that employers will behave strategically when faced with the threat of unionization. Employers can ensure that unionization does not take place if they pay wages at least as high as those workers would obtain if they organized. As long as the process of organization entails some costs to workers or unionization reduces rents, it will be optimal for employers to pay workers more than their alternative wage so as to match their expected utility from unionization, and thus avoid unionization altogether. This would make union organization possible only in those firms where unions improved productive efficiency, or provided benefits to workers that employers could not offer themselves. If we allow that employers may be better informed than workers about their firms' prospects, unionization can take place in equilibrium, even if it does not have any positive effect on efficiency. If workers do not know with certainty what they would obtain if they organized, their expectations will be too optimistic in those firms with less than average profitability. These firms may thus find it too costly to prevent unionization, and may allow union formation in order to signal their low profitability to workers.

The increase in wages required to prevent unionization, however, does not reduce employment, as predicted by the standard union threat view. By increasing employment, the firm reduces the wage it needs to pay to dissuade workers from unionizing, because a higher em- 
ployment level is likely to decrease both the negotiated union wage, and workers' probability of employment after organization. The marginal cost of labor is thus lower than the wage, and falls as employment increases. This strategic motive to increase employment more than compensates for the rise in wage costs, so that no reduction in employment takes place despite the higher wages. However, if firms have private information about their profitability, less profitable firms may find it optimal to employ fewer workers to distinguish themselves from profitable firms, for which the reduction in employment would be more costly. Less profitable firms would thus lay off workers to convince the remaining ones to moderate their wage demands.

While there exists a large empirical literature that attempts to measure the effects of unions on wages and firm performance, ${ }^{5}$ the theoretical work on the determinants of unionization and its effects on the behavior of nonunion firms is surprisingly scarce. In a seminal contribution, Sherwin Rosen (1969) first introduced a simple reduced-form model of wage determination in which nonunion firms take into account the effect of their wage choice on the probability of unionization. William Dickens (1986) followed on Rosen's contribution, and developed a formal model of wage and employment determination in the presence of a unionization threat. Using a cooperative game theory approach, Dickens described the wage and employment policy that would avoid unionization at a minimum cost, and was the first (and last, to the best of my knowledge) to raise the possibility that the cost-minimizing choice may involve overemployment. Unfortunately, Dickens did not ask whether, or under which circumstances, it may be optimal to let workers form a union, and therefore his model cannot provide predictions about unionization. The papers by Freeman (1986), Freeman and Kleiner (1990), Blanchflower and Freeman (1992), and Blanchflower (1997) mentioned above have tried to explain the extent of unionization as a function of the expected wage gains from collective bargaining. ${ }^{6}$ In these papers, expected wage gains from collective bargaining affect the demand for union services by workers, and employers' incentives to resist unionization attempts in opposite directions, so that the relationship between the union wage premium and organization cannot be predicted a priori. The reduced-form models put forth in these papers, however, take the wage premium as given, and hence cannot account for the effect that the threat of collective action has on the determination of this wage premium. The only attempt to simultaneously explain unionization, employment, and wages is the work by Edward Lazear (1983). In his model, workers announce an industry-wide wage demand, and employers decide whether to accept that demand (thus becoming "unionized") or to resist unionization at a cost. Therefore, employers are given a passive role, while yetunorganized workers are able to make an industry-wide wage demand. The model thus provides a better description of a unionized industry with centralized bargaining in which employers can deviate from the collective bargaining agreement at a cost, than of an industry with either no

\footnotetext{
${ }^{5}$ For surveys of this literature, see Lewis (1986), Pencavel (1991), Hirsch (1991), and Booth (1995). Section VI below discusses some of the results of the empirical literature.

${ }^{6}$ In a related effort, Farber (1990) attempted to decompose the changes in union density into changes in the demand for and the supply of union services.
} 
or decentralized bargaining, in which workers can organize at the firm level. In the present paper, I study the simultaneous determination of wages, employment, and unionization, while, at the same time, incorporating the strategic wage setting behavior first proposed by Rosen and Dickens.

The paper is organized as follows. Section II presents a simple version of the model in which employment choices are given, and the firm only decides what wage to set. Section III extends this simple model to analyze the determination of employment. Sections IV and V study wage and employment determination when firms have private information about their profitability, and section VI reviews the available evidence. Finally, section VII offers some suggestions for future research, and section VIII cocludes.

\section{Strategic Wage Determination and Unionization}

\section{A The Model}

Consider a firm which operates for two periods, and hires labor from a pool of identical workers. For simplicity, I will assume in this section that the firm does not have any discretion over employment if it operates: In order to produce its output the firm has to employ a fixed number of workers.

In the first period, the firm offers a wage $w^{0}$ to the pool of potential workers, who act as wage takers and can obtain a wage $\bar{w}$ outside of the firm. If no worker accepts work at that wage, the firm closes, and obtains zero revenues. Otherwise, the jobs are filled, and employees acquire firm-specific skills through on-the-job training. The skills acquired imply that, in the second period, the value of the relationship between the firm and an existing worker, $v$, is higher than the value that could be obtained by hiring an alternative worker that period, $\bar{v}^{7}$

At the beginning of the second period, the firm offers a wage $w$ to its employees, who then have three options: reject the wage and leave the firm, accept to work at the offered wage, or establish a union, which entails organization costs $c$.

Note that the model assumes that workers start unorganized. After learning the firm's wage policy, they decide whether to unionize. This assumption tries to capture how actual labor markets work, at least in the U.S., where, at their inception, firms are generally union free. Although an employer could choose to recognize a union for the conduct of collective bargaining before the firm is in operation, this is seldom done, and, in any case, it would be solely the employer's choice, as no legal rule compels her to do so. Further, it is reasonable to expect workers to assess what they can earn without a union, before deciding to join one. Workers' organization decision is more a response to employers' policies than a spontaneous

\footnotetext{
${ }^{7}$ Even in the absence of firm-specific skills, firing and hiring costs may create a wedge between the value to the firm of an existing employee, and that of a new worker. Note that if $v=\bar{v}$, there would be no room for bargaining.
} 
impulse to be a union member.

Note also that the process of union organization is left unmodelled: workers can organize to bargain collectively simply by incurring organization $\operatorname{costs} c$. A more realistic interpretation is that $c$ are the costs workers would incur at the equilibrium of an organization game in which they would devote time and effort to organizing, and management would fight the organization attempt. Therefore, $c$ includes not only the direct costs associated with the organizing effort (or the payment to an established union for its services), but also the expected losses due to management's retaliation against union organizers. Modelling this organization game is, however, beyond the scope of this paper. Instead, I take the outcomes of the organization game as parameters, imposing as little structure as possible on the relations between different parameters.

If a union is established, collective bargaining takes place, resulting in a wage $w^{u}>0$, which, in this section, is taken as a parameter of the model. Therefore, workers are able to extract some of the quasi-rents only if they bargain collectively, and none if they do so individually. This is a simplifying assumption: the analysis applies to all cases in which workers' bargaining power increases if they bargain collectively. ${ }^{8}$

Moreover, the presence of a union may also affect the value of the relationship between the firm and its workers. If a union is organized, this value becomes $v^{u}$. Although the model is static, $v$ and $v^{u}$ are better understood as the net present value of a long term relationship between the firm and its workers. Unionization can affect this value through a variety of channels. It can reduce production efficiency directly, by imposing restrictive work practices, or, in contrast, enhance productivity by facilitating communication between workers and management or improving morale. It can also affect input choices by distorting relative prices; reduce rents if the firm devotes resources to fighting the organization attempt; provide direct utility or disutility to workers and management; or change the set of self-enforceable contracts available, ${ }^{9}$ to name a few possibilities. Therefore, $v^{u}$ will generally differ from $v$.

\section{B Union (Non) Formation under Complete Information}

Employers can always guarantee that workers remain nonunion: If they offer a wage $w$, such that $w>w^{u}-c$, workers have no incentive to organize. On the other hand, offering $w<w^{u}-c$ would trigger organization. Since both outcomes are feasible, unions will only form where organization is less costly to the firm than union avoidance. Proposition 1 shows that, under complete information, this can never be the case unless unions increase rents.

\footnotetext{
${ }^{8}$ See Stole and Zwiebel (1996) and Segal (1999) for a theoretical analysis of individual wage bargaining, and the conditions determining the relative advantage of collective versus individual bargaining.

${ }^{9}$ Many aspects of the employment relationship are implicit, so that the set of feasible contracts is restricted to those whose provisions regarding these aspects are incentive compatible. By giving workers a powerful device, the strike, to punish deviations from implicit agreements, the presence of a union may expand the set of incentive compatible contracts. It can be efficient for employers to ba able to "tie their hands" so as not to renege on their promises.
} 
Proposition $1 i$. If $v_{u}-c \leq v$, at the unique subgame perfect equilibrium of the game the firm offers $w^{u}-c$ in the second period, and workers accept the offer.

ii. If $v_{u}-c>v$, organization takes place with certainty.

Proof. i. If the firm offered $w<w^{u}-c$ in the second period, workers would organize with certainty, and the firm's payoff would be $\pi^{u}=v^{u}-w^{u}$. By offering $w=w^{u}-c+\varepsilon$, where $\varepsilon>0$, the firm ensures that workers do not organize, and its payoff is $\pi=v-w^{u}+c-\varepsilon$. If $v^{u} \leq v+c$, then for $\varepsilon$ small enough, $\pi>\pi^{u}$. For $w=w^{u}-c$, workers' equilibrium strategy cannot involve a positive probability of organization, as the same argument would apply. Therefore, in equilibrium, workers must accept any $w \geq w^{u}-c$. Similarly, no strategy implying a positive probability of rejection in the first period could be part of an equilibrium profile, as the firm would profitably deviate by offering a slightly higher $w^{0}$. It follows that the unique equilibrium strategies are: (i) the firm offers wage $w^{0}=-\left(w^{u}-c\right)$ in the first period, and $w=w^{u}-c$ in the second period; (ii) workers accept any $w^{0}$ such that $w^{0} \geq-\left(w^{u}-c\right)$, and any $w$ such that $w \geq w^{u}-c$. If $w<w^{u}-c$, workers establish a union. If $v_{u}-c>v$, it is straightforward to show that $\pi^{u}>\pi$ for any $\varepsilon \geq 0$, which proves part ii.

Proposition 1 implies that no unions will appear in equilibrium unless they are efficient. In the absence of contracting problems, this result is hardly surprising, and can be viewed as a special case of the Coase Theorem. However, it conflicts with the strong prior that unions are inefficient because they distort input choices, either directly, through restrictions on work practices (like manning restrictions, or strict job classifications), or indirectly, by altering relative prices. In fact, in the model, even if unions were merely redistributive (as in efficient bargaining models of collective bargaining), the presence of organization costs would preclude union formation. Only if unions increase rents sufficiently is it optimal for management not to prevent organization. Note that this does not imply that employers prefer unionization to the competitive outcome, as, unless the positive effect of unions is substantial, profits will be lower in unionized firms than in nonunion firms paying the alternative wage. However, when workers can unionize, the firm cannot pay the alternative wage and remain nonunion.

Although the organization game is not analyzed in this paper, note that it is always better for management to prevent unionization by increasing the wage, than by letting the organization attempt happen, and then defeating it. If the outcome of the organization game were, say, that the union is defeated with high probability, the expected payoff from unionization (as represented by $w^{u}$ ) would be low. This would just make it cheap for the employer to prevent unionization by offering $w^{u}-c$.

If $c$ is large, unions may not always form when they increase rents (as it can be that $v^{u}>v$, but $v^{u}-c<v$ ), but proposition 1 has the optimistic implication that workers will not join unions when it is inefficient to do so. In a later section, I will discuss the robustness of this result in a more realistic framework, in which employers have better information than workers 
about the firm's profit prospects. However, I will first analyze how the threat of unionization affects employment determination in the perfect information context.

\section{Employment Determination under the Threat of Unioniza- tion}

As discussed in the introduction, the view that the threat of unionization may increase nonunion wages has generally been taken to imply that it will also cause employment in the nonunion sector to fall, as nonunion employers move up their labor demand curve. ${ }^{10}$ In this section, I extend the simple model presented above to evaluate this claim, and I check whether proposition 1 also applies in this more general framework.

Let now the firm decide how many workers to hire at the beginning of the fist period, $l^{0}$. During this first period, workers yield revenues $R_{0}\left(l_{0}\right)$, and acquire firm-specific skills. Therefore, at the end of the first period, existing employees become more valuable to the firm than alternative workers, that is, $R(l)>\bar{R}(l)$, where $R(l)$, and $\bar{R}(l)$ are the revenues the firm can obtain in the second period if it employs $l$ skilled, or unskilled workers, respectively. $R$ and $\bar{R}$ are increasing, concave and twice continuously differentiable functions, with $R(0)=\bar{R}(0)=0$. $R^{\prime}$ is also assumed to be concave. ${ }^{11}$ Finally, the productivity of skilled workers is higher than that of unskilled workers, that is, $R^{\prime}(l)>R_{0}^{\prime}(l)$ for all $l$.

At the beginning of the second period, the firm decides how many employees to retain, $l$, and offers them a wage $w$. These employees can unionize by incurring organization costs $C(l)$, which may vary with the number of employees at the firm. If they do so, collective bargaining takes place, and, as a result, a wage $w^{u}(l)$ is set, and $l^{u}(l) \leq l$ employees remain in the firm. Both $l^{u}$ and $w^{u}$ are expressed as functions of $l$, since the bargaining outcome may conceivably depend on the level of initial employment. Hereafter unions will be assumed to have no direct effect on productive efficiency, that is, $R^{u}\left(l^{u}\right)=R\left(l^{u}\right)$, so that the superscript will be omitted. It is important to note that this does not imply that unions cannot be inefficient: they may still affect efficiency greatly by distorting input choices.

\section{A The Collective Bargaining Stage}

If a union is formed, it negotiates with management over wages and, possibly, employment. The result of this negotiation will depend on the objectives of the union, and the way in which bargaining takes place. For simplicity, this paper will assume that the union maximizes the expected utility of its risk neutral workers, and that it is able to impose its wage demands on employers. Employers, in turn, keep their prerogative to set employment at will given the wage set by the union. This "monopoly union" model of collective bargaining is perhaps the model

\footnotetext{
${ }^{10}$ For a textbook exposition of this view, see Ehrenberg and Smith (1997).

${ }^{11}$ This assumption is made only for tractability. It could be dropped at the cost of unnecessary complexity.
} 
most widely used in applications. Moreover, it has the attractive feature, for our purposes, that collective bargaining outcomes are highly inefficient. The following lemma summarizes its main properties, which are also depicted in figure 2 .

Lemma 1 In the monopoly union model:

1. $l^{u}(l)=l$, for $l \leq l^{u *}$, and $l^{u}(l)=l^{u *}$, for $l>l^{u *}$

2. $l^{u *}<l_{c}=R^{\prime-1}(\bar{w})$

3. $w^{u}(l)=R^{\prime}(l)>\bar{w}$, for $l \leq l^{u *}$, and $w^{u}(l)=R^{\prime}\left(l^{u *}\right)>\bar{w}$, for $l>l^{u *}$

4. $R\left(l^{u}(l)\right)-l^{u}(l) w^{u}(l)$ is increasing in $l$ for $l \leq l^{u *}$, and constant for $l>l^{u *} \cdot{ }^{12}$

Proof. (All omitted proofs can be found in the appendix.)

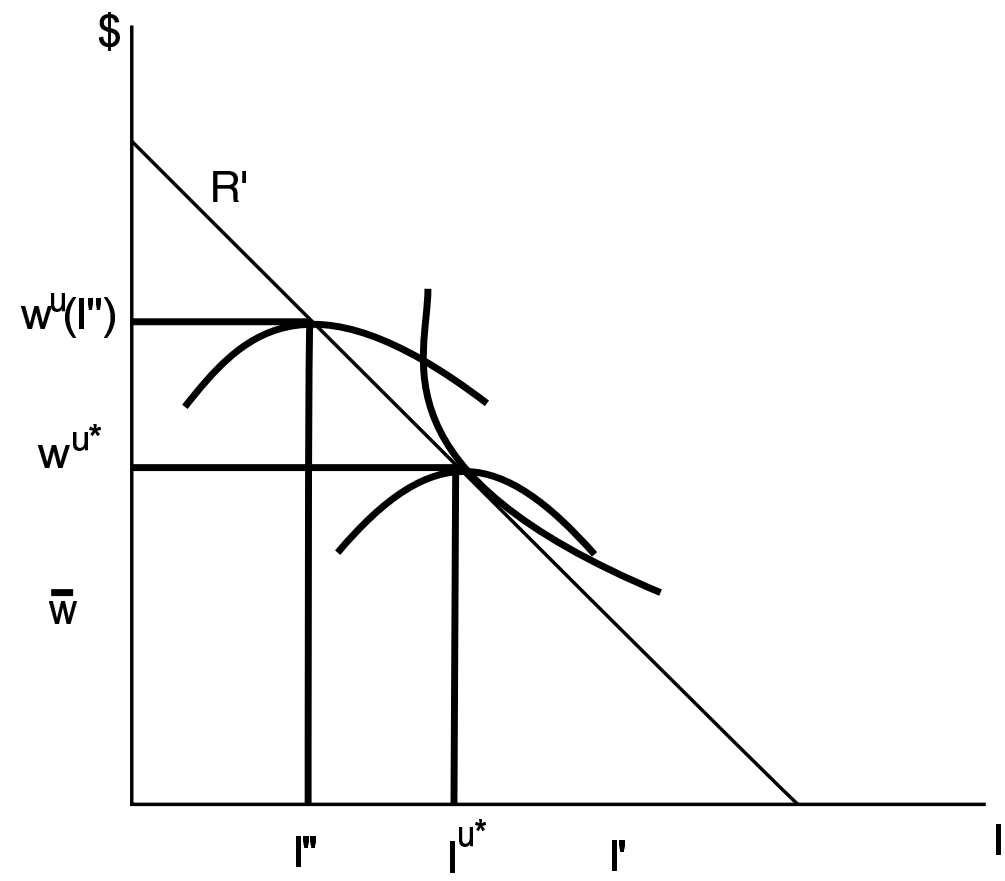

Figure 2: Monopoly Union Model

The choice of this specific bargaining model is made for expositional clarity. It can be shown that all the results in this paper can be extended to a more general framework in which workers are allowed to be risk-averse, and the bargaining process need only satisfy a monotonicity property. This property requires that the trade off between wages and employment depend on the level of membership: When membership (initial employment) is low, the union can

\footnotetext{
${ }^{12}$ Concavity of $R^{\prime}$ guarantees the uniqueness of the bargaining outcome. If $R^{\prime}$ is not concave, $l^{u}(l)$ may not be a function, and part 1 of the lemma would not hold. This would made other proofs more cumbersome, but would not alter the results.
} 
obtain high wages while guaranteeing the employment of all its members. As employment increases, marginal workers become less productive, so that unions have to agree to lower wages to guarantee full employment. Finally, for some level of membership, the union prefers to accept some unemployment rather than agreeing to further lowering the wage earned by its employed members. The most commonly used models of collective bargaining, namely the right-to-manage, and the efficient bargaining models ${ }^{13}$ satisfy this monotonicity property. ${ }^{14}$

\section{B The Optimality of Union Avoidance}

The intuition behind proposition 1 still holds if the firm is allowed to determine the level of employment. As long as the firm can mimic the union outcome, paying its workers not to unionize guarantees profits at least as high as those the firm would obtain if unionized, so that unions do not form in equilibrium. The next proposition proves the validity of this intuitive argument, and gives an expression for the wage necessary to prevent union formation.

Proposition 2 Let $l^{*}$ be the optimal employment choice. Then, at the unique subgame perfect equilibrium of the second period subgame, the firm offers

$$
w\left(l^{*}\right)=\frac{l^{u}\left(l^{*}\right)}{l^{*}} w^{u}\left(l^{*}\right)+\frac{l^{*}-l^{u}\left(l^{*}\right)}{l^{*}} \bar{w}-\frac{C\left(l^{*}\right)}{l^{*}},
$$

if $w\left(l^{*}\right)>\bar{w}$, and $\bar{w}$ otherwise, and workers accept the wage offer.

According to proposition 2, the threat of unionization forces employers to pay workers more than their reservation wage. Because of this increase in the cost of labor, employers will tend to hire less workers. This effect is the one usually considered in discussions of the union threat. However, note that the wage required to prevent unionization itself depends on the level of employment, so that employment, and not just the wage, becomes a strategic variable: employment will be set taking into account its effect on workers' incentives to join a union. The next section studies how this strategic motive and the wage increase caused by the union threat interact to determine the firm's employment choice.

\section{Employment Determination}

When determining the level of employment in the second period, firms will be constrained by their initial choice of employment, $l^{0}$, as they cannot hire extra workers with specific skills that period. To focus on the pure effect of the threat of unionization on employment, however, I

\footnotetext{
${ }^{13}$ The right-to-manage model (of which the monopoly union model is a special case) assumes that the union and the employer negotiate over the wage, while employment is unilaterally set by the latter. The model is justified on the grounds that, under American labor law, the employer is guaranteed the right to set employment at will, and that collective bargaining agreements rarely include explicit employment clauses. The efficient bargaining model, on the other hand, assumes that the employer and the union will strike an efficient agreement, which generally implies that they bargain jointly over wages and employment.

${ }^{14}$ I would gladly provide the proof of this statement upon request.
} 
will abstract from this constraint, and assume that the firm can set $l$ unrestricted by its initial choice of employment. This is a good approximation to the case in which workers expected tenure at the firm is substantially longer than the apprenticeship period. Moreover, taking into account the first period, while making the model more complex, does not qualitatively affect the results.

Let $\left(P_{c}\right)$ be the problem of a firm with production function $R$ hiring from a competitive labor market:

$$
\operatorname{Max}_{l} R(l)-\bar{w} l,
$$

The solution to this problem is $l_{c}$, defined in lemma 1, which satisfies: $R^{\prime}\left(l_{c}\right)=\bar{w}$.

A firm facing a threat of unionization cannot take the wage as given. Proposition 2 implies that the firm will instead solve $\left(P_{T}\right)$ :

$$
\begin{array}{rl}
\operatorname{Max}_{l} & R(l)-w(l) l \\
\text { s.t. } & w(l)=\max \left\{\frac{l^{u}(l)}{l}\left(w^{u}(l)-\bar{w}\right)+\bar{w}-\frac{C(l)}{l}, \bar{w}\right\} .
\end{array}
$$

Let $l^{*}$ denote the solution to this problem. ${ }^{15}$

Proposition 3 If $C(l)$ is nondecreasing in $l$, then $l^{*} \geq l_{c}$ and $w \geq \bar{w}$. If $C(l)$ is strictly increasing in $l$, and $\frac{l^{u *}}{l_{c}}\left(w^{u *}-\bar{w}\right)+\bar{w}-\frac{C\left(l_{c}\right)}{l_{c}}>\bar{w}$, then $l^{*}>l_{c}$ and $w \geq \bar{w}$.

Proposition 3 states that both the wage and employment are higher under the threat of unionization than in the competitive case. This possibility, first proposed by Dickens (1986), ${ }^{16}$ runs counter the two prevailing views of the effect of unions on the wages and employment of nonunion workers discussed in the introduction. On the one hand, once we drop the assumption that employers are wage takers (and the very presence of unions in an industry should lead us to do so), it becomes difficult for unionization to lower nonunion wages as predicted by the crowding view. To do so, the supply shift due to the workers displaced from the union to the nonunion sector should be large enough to compensate for the upward shift in the wageemployment schedule caused by the union threat.

On the other hand, despite raising nonunion wages, the threat of unionization does not reduce employment as predicted by the conventional union threat view. The explanation for this apparently counter-intuitive result is that, because of the threat of unionization, the marginal cost of an extra worker is not equal to the wage, so that employment is not on the competitive

\footnotetext{
${ }^{15}$ By assuming that the firm pays the same wage to all workers, I am implicitly ruling out the possibility that the firm can ask new hires to pay to obtain a job. The role of this type of payment is discussed below. Note also that we should also include a participation constraint for the firm that required profits to be greater than those that the firm could obtain if it hired unskilled workers at wage $\bar{w}$. I will assume that this participation constraint holds for the relevant range of $l$.

${ }^{16}$ Although using a different modelling strategy, Dickens also obtains that unionization may increase both employment and wages. However, since, in his model, the choice of employment does not influence the bargaining outcome (or rather, the set of bargaining outcomes), he concludes that the opposite result is also possible.
} 
labor demand curve. To avoid unionization, employers are forced to set the wage equal to the expected utility from organization. Therefore, if the presence of an extra worker decreases this expected utility, the marginal cost of labor will be less than the going wage. Lemma 1 ensures that this is the case: hiring an extra worker leads either to lower union wages (if $l<l^{u *}$ ) or to a greater probability of unemployment (if $l>l^{u *}$ ). In particular, if $l>l^{u *}$, increases in employment do not affect the negotiated wage, so, if $C(l)$ were constant for these levels of employment, the cost of the marginal worker would be just $\bar{w}$, as this marginal worker would be unemployed if organization took place.

Figure 3 displays the labor demand curve $\left(R^{\prime}\right)$ the wage-employment curve $(w(l))$, and the marginal cost curve $\left((w(l) l)^{\prime}\right)$. The optimal employment level lies at the point where the marginal revenue and the marginal cost curves intersect.

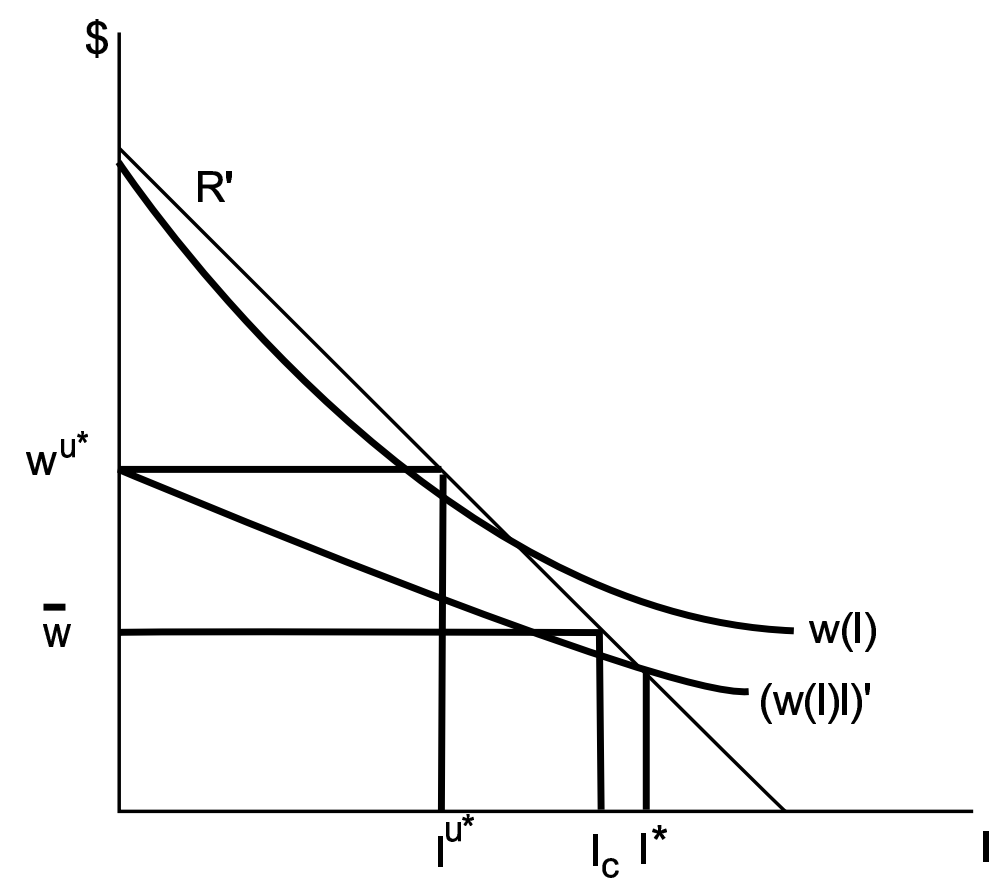

Figure 3: Employment Determination

As mentioned above, the first period has not been included in the analysis. This omission could be relevant for two reasons. First, unskilled workers may have lower marginal productivity, so that the firm may want to employ few of them in the first period, thus limiting the choices in the second period. And second, the firm can use $w_{0}$ to make up for the rents lost to workers in the second period. Because workers will accept any $w_{0}$ such that their expected earnings at the firm are at least as large as what they could obtain elsewhere, the firm can recover ex ante the rents that will be lost to workers in the second period by setting a low enough $w^{0}$. However, it can be shown that neither of these considerations would lead firms to employ less workers than in the competitive case.

Interestingly, Stole and Zwiebel (1996) and (1996b), have also shown that overemployment 
will result from a model in which, due the presence of quasi-rents, wages are determined through individual bargaining between the employer and her workers. In that case, as in this section, hiring above the competitive level allows the employer to strike a better wage deal.

\section{Union Formation under Asymmetric Information}

According to propositions 1 and 2, unionization takes place only when it increases the surplus associated with the relationship between the firm and its workers. This result was predicated on the assumption that management and workers have the same information about the expected outcome of unionization. This assumption, however, is problematic. First, it may not be representative of the situation in which most workers find themselves when deciding whether to unionize. One of the main roles of managers is to evaluate the profitability of different courses of action, and their own choices greatly influence future profitability. Therefore, it is likely that managers can form a better assessment of the firm's profit prospects than workers, who lack managers' time and skills, and their access to profit-relevant information. Second, assuming symmetric information may be essential to rule out inefficient unionization: As the literature on bargaining with asymmetric information shows, ${ }^{17}$ the presence of asymmetric information may lead to inefficient outcomes, which would not be reached if all parties had the same information.

Therefore, this section analyzes the firm's wage determination problem when managers are better informed than workers about the expected outcome of unionization, and the next section extends the model to study employment determination.

As in the complete information case, the model consists of two periods. In the first period, all firms and workers are identical, as management has not yet learned what quasi-rents a skilled worker would generate, and workers have not yet acquired firm-specific skills. To simplify, I assume that firms can be of only two types, high-value $(H)$, and low-value $(L)$ firms, with $v_{H}>v_{L}$, and $v_{H}^{u}>v_{L}^{u}$. Since we are interested in the possibility of inefficient union formation, it will be assumed that, for any type $i, v_{i} \geq v_{i}^{u}$. The commonly known distribution of types is given by $q$, the probability that a firm is high-value. At the beginning of the first period, management offers a wage $\left(w^{0}\right)$, and workers decide whether to accept the wage and join the firm. After workers join the firm, management learns the firm's type, and workers accumulate firm-specific human capital.

In the second period, management makes a new wage offer to the employed workers $(w)$, who, not knowing the firm's type, do not know the wage that would result from unionization. Based on the distribution of types, and the wage offer made by the firm, workers update their beliefs about the firm's type, and decide whether to accept the wage offer or to organize a union.

If a union formed, the bargaining outcome would depend on the union's assessment of the firm's type. Since union officials typically have time and skills to assess firm performance

\footnotetext{
${ }^{17}$ For a review of this literature, see Kennan and Wilson (1993)
} 
not available to individual workers, it is reasonable to assume that they will learn additional information with which to update workers' beliefs. I will assume that, in fact, the union is able to observe the firm's type. This assumption is made only for simplicity. All that is needed for the results is that either the union observes some noisy signal of the firm's type, or, even if it has the same information than individual workers, that the outcome of the asymmetric information bargaining game between the firm and the union involves some separation. ${ }^{18}$ The result of union-management bargaining is thus $w_{H}^{u}$ in high-value firms, and $w_{L}^{u}$ in low-value firms, where $w_{H}^{u} \geq w_{L}^{u}$.

Figure 4 depicts the asymmetric information model.

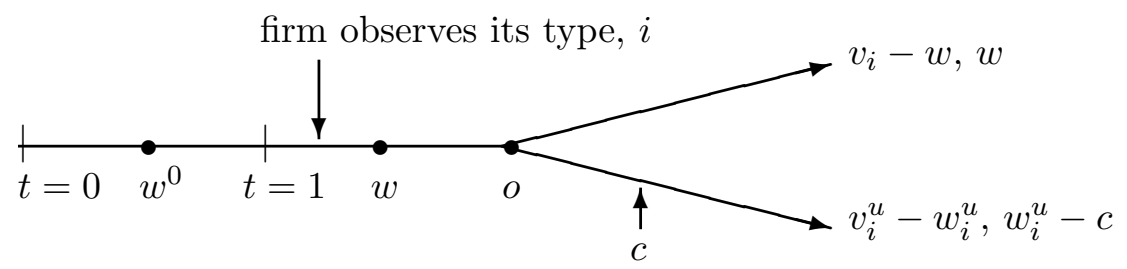

Figure 4: Asymmetric Information Time-line

Apart from the increase in wages, unionization may impose further costs on firms if it reduces surplus. Two assumptions will be made about the net effect of unions on wages and total surplus. The first is that unionized $\mathrm{H}$ firms earn higher profits than unionized L firms $\left(v_{H}^{u}-w_{H}^{u} \geq v_{L}^{u}-w_{L}^{u}\right) \cdot{ }^{19}$ The second assumption is that the total cost of unionization is still higher for $\mathrm{H}$ firms once the effect on rents is taken into account $\left(\left(v_{H}-v_{H}^{u}\right)+w_{H}^{u}>\left(v_{L}-v_{L}^{u}\right)+w_{L}^{u}\right)$. That is, even if unions reduced rents more in L firms, this effect would not be larger than the effect of unionization on the wage bill. ${ }^{20}$ These two assumptions are summarized in the following one:

Assumption (Sorting). $0 \leq\left(v_{H}^{u}-w_{H}^{u}\right)-\left(v_{L}^{u}-w_{L}^{u}\right) \leq\left(v_{H}-v_{L}\right)$.

In the usual terminology, this assumption is a sorting, or single crossing, ${ }^{21}$ condition, as it implies that $\mathrm{H}$ firms are willing to pay more to reduce the probability of organization.

To see how the presence of asymmetric information modifies the results in previous sections, first note that, if no information is credibly communicated to workers, their expected wage from

\footnotetext{
${ }^{18}$ In fact, most results -all involving separating equilibria- would still hold, even if none of these requirements held.

${ }^{19}$ Assuming the contrary would be highly problematic. If $v_{H}^{u}-w_{H}^{u}<v_{L}^{u}-w_{L}^{u}$, then $\mathrm{H}$ firms could, in principle, waste money (or adopt L's inferior behavior) to become like an L firm, which would erase the difference.

${ }^{20}$ The opposite assumption would imply that unions have a (sufficiently) greater proportional effect on rents in L firms.

${ }^{21}$ Graphically, it implies that the isoprofit lines of $\mathrm{H}$ and $\mathrm{L}$ firms on the space of wages and probabilities of organization can cross only once.
} 
unionization is $q w_{H}^{u}+(1-q) w_{L}^{u}-c$. If $q$ or $w_{H}^{u}-w_{L}^{u}$ is high enough, this expected wage will be high, making it very costly for L firms to avoid organization. L firms will try to signal their low value to workers but they cannot credibly do so while at the same time avoiding organization, as in that case it would clearly be optimal for $\mathrm{H}$ firms to imitate them. Therefore, if the ex ante expected wage from organization is high enough, the only alternative for $\mathrm{L}$ firms is to trigger organization, thus revealing their type to the union. $\mathrm{H}$ firms will still find it profitable to avoid the risk of unionization, so that only L firms become unionized. If the ex ante expected union wage is not too high, however, L firms may avoid organization with positive probability by paying the same wage offered by $\mathrm{H}$ firms. In this case, if workers use mixed strategies, unionization can occur in $\mathrm{H}$ firms if the probability with which workers organize is low enough. The analysis below formalizes this argument.

Let $\rho: \Re_{+} \rightarrow[0,1]$ represent the worker's beliefs after observing a wage offer, so that $\rho(x)=\operatorname{Pr}\left(v=v_{H} \mid w=x\right)$ is the probability the worker assigns to the firm being high-value, given that a wage $x$ has been offered.

Let $o: \Re_{+} \rightarrow[0,1]$ be the behavioral strategy of the worker in the second period, where $o(w) \in[0,1]$ specifies the probability with which the worker will organize given that the wage $w$ was offered.

Let $P_{i}$ be the behavioral strategy (a probability measure over wages) of a type- $i$ firm in the second period, and let $S_{i}$ be the support of $P_{i} \cdot{ }^{22}$

Lemma 2 There does not exist a Perfect Bayesian Equilibrium (PBE) in which $H$ firms become unionized with certainty.

Proof. At any equilibrium, it must be the case that, for $w>w_{H}^{u}-c, o(w)=0$. Thus, if an $\mathrm{H}$ firm offers $w^{\prime}=w_{H}^{u}-c+\varepsilon$, for $\varepsilon>0$, its payoff is $v_{H}-w_{H}^{u}+c-\varepsilon$, which, for $\varepsilon$ small enough, will always be higher than $v_{H}^{u}-w_{H}^{u}$.

Therefore, $\mathrm{H}$ firms always find it more profitable to avoid organization altogether rather than offering some wage for which organization would occur with certainty. The next proposition shows that equilibria in which $\mathrm{H}$ firms avoid organization, and L firms are organized with positive probability always exist. Note that, in what follows, I will discuss only the second period subgame. The first-period wage will be set so as to make workers indifferent between the job and alternative employment, or, if such a wage were not feasible, to the minimum wage feasible.

Proposition $4 i$. There exist fully revealing PBE in which L firms get organized with probability

$$
u_{L s} \in\left[\frac{w_{H}^{u}-w_{L}^{u}}{\left(w_{H}^{u}-w_{L}^{u}\right)+v_{H}-v_{H}^{u}+c}, \min \left\{1, \frac{w_{H}^{u}-w_{L}^{u}}{v_{L}-v_{L}^{u}+c}\right\}\right],
$$

\footnotetext{
${ }^{22}$ Although $P_{i}$ is defined over sets, abusing notation, I will write $P(w)$ to express $P(\{w\})$ when $w$ is played with positive probability.
} 
and $H$ firms prevent organization with certainty by offering a wage $w_{H}=w_{H}^{u}-c$.

ii. No other fully revealing PBE exist.

If the ex ante expected utility from unionization is large, or workers beliefs are such that, when faced with a low wage off the equilibrium path, they attribute a high enough probability to $\mathrm{H}$ firms having chosen that wage, a separating equilibrium will obtain. Since it is cheaper for L firms to endure unionization, they may choose to do so to "signal" their type, and avoid being taken as an $\mathrm{H}$ firm. However, if the costs of unionization to L firms are relatively large, and the ex ante expected wage is not too high, L firms might find it optimal not to signal their type. As the next proposition show, if L firms prefer to pay the ex ante expected wage than to become unionized with certainty, pooling equilibria will exist.

\section{Proposition 5 1. If}

$$
\text { (1) } v_{L}-\left(q w_{H}^{u}+(1-q) w_{L}^{u}-c\right) \geq v_{L}^{u}-w_{L}^{u} \text {, then: }
$$

i. There exist pooling $P B E^{23}$ in which both types of firms avoid organization with certainty, and the wage is

$$
w_{p} \in\left[q w_{H}^{u}+(1-q) w_{L}^{u}-c, \min \left\{v_{L}-v_{L}^{u}+w_{L}^{u}, w_{H}^{u}-c\right\}\right] .{ }^{24}
$$

ii. There exist pooling PBE in which both types of firms set $w_{p}=q w_{H}^{u}+(1-q) w_{L}^{u}-c$, and face a positive probability of organization.

2. If condition (1) does not hold, no pooling equilibria exist.

Therefore, if it is not too costly for L firms to pass as $\mathrm{H}$ firms, pooling equilibria, at which both firms face the same probability of organization, will exist. At some of these equilibria, $\mathrm{H}$ firms take the risk of becoming unionized in exchange for a low wage. In others, both $\mathrm{H}$ and $\mathrm{L}$ firms avoid organization with certainty. Therefore, propositions 4, and 5 together imply that, against the widely held view that unionization is more likely in more profitable firms, the probability of organization is never higher in $H$ firms than in L firms. In the next section, I discuss this result in greater detail. ${ }^{25}$

\footnotetext{
${ }^{23}$ It is well known that forward-induction refinements, like the Intuitive Criterion (Cho and Kreps (1987)) can eliminate a great number of equilibria in signaling games. The equilibria in this section, however, are immune to this sort of refinements. If a $\mathrm{H}$ firm deviated from its equilibrium behavior by choosing a wage $w<w_{H}^{u}-e$ that could not have been preferred by a L firm to its equilibrium play, and thus signaled its type, workers would unionize: knowing that the firm is $\mathrm{H}$, their payoff from organizing, $w_{H}^{u}-e$, is greater than the offered wage.

${ }^{24}$ However, note that, if we restricted beliefs to be nondecreasing in the wage offer, all equilibria with $w_{p}>$ $q w_{H}^{u}+(1-q) w_{L}^{u}-c$ would be eliminated (as they would require $\rho(w)>q$ for $w<w_{p}$ ), and the only pooling wage would be $w_{p}=q w_{H}^{u}+(1-q) w_{L}^{u}-c$.

${ }^{25}$ In this section, we have not considered all possible equilibria. Apart from the equilibria analyzed in this section, Ruiz-Verdú (2000) shows that there exist equilibria in which firms play mixed strategies, but their existence does not change this result.
} 


\section{A Implications}

\section{a Unionization and Rents}

It is often argued that workers will be more likely to join unions in those firms or industries earning larger rents (e.g. Hirsch (1991), p. 60), as the demand for union services should be greater where the potential gains from organization are larger. This would be true if firms did not act at all to prevent organization, or if their actions were unrelated to rent size. However, large gains to workers mean large losses to the firm. Therefore, it is reasonable to expect profitable employers to resist union organization more strongly, a possibility explored in a series of papers ${ }^{26}$ which have investigated employers' responses to union organization attempts. The analysis in those papers, however, does not yield any a priori prediction regarding the net effect of rents on the probability of organization. The model in this paper, in contrast, looks at the actions that employers may take prior to organization to prevent it from being attempted in the first place, ${ }^{27}$ and yields the prediction that the probability of unionization within a group of otherwise identical firms is negatively related to the size of the rents to be divided between the firm and its employees.

No prediction can be made a priori about the relationship between ex ante expected rents and unionization (or, put differently, about the probability of organization across firms known to differ ex ante in their expected rents), as the probability of organization does not depend on the location, but on the shape of the distribution of rents. Only if rents are so low (and consequently union wages too) that unionization is ex ante unprofitable for workers independently of the wage offer, will knowledge of ex ante expected rents be informative about the probability of organization. A fall in rents known to to make unionization unprofitable for any wage is certain to bring the probability of organization down to zero.

\section{b Determinants of Unionization}

The probability of organization, for given parameter values, will be determined by the probability with which organization can take place in different types of equilibrium, and the types of equilibrium that can obtain given those parameter values. As shown in the previous section, there are two possible regimes, depending on whether condition (1) holds.

1. Separation. $\left(v_{L}-\left(q w_{H}^{u}+(1-q) w_{L}^{u}-c\right)<v_{L}^{u}-w_{L}^{u}\right)$. Proposition 4 shows that in this case $\mathrm{H}$ firms avoid organization with certainty, and L firms become organized with probability $u_{L s}$. The ex ante probability of organization is thus

$$
u_{s}=(1-q) u_{L s} \in\left[\frac{(1-q)\left(w_{H}^{u}-w_{L}^{u}\right)}{\left(w_{H}^{u}-w_{L}^{u}\right)+v_{H}-v_{H}^{u}+c}, \min \left\{(1-q), \frac{(1-q)\left(w_{H}^{u}-w_{L}^{u}\right)}{v_{L}-v_{L}^{u}+c}\right\}\right]
$$

\footnotetext{
${ }^{26}$ See Freeman (1986), Freeman and Kleiner (1990), or Abowd and Farber (1990).

${ }^{27}$ As discussed in section II, this does not mean that the model deprives managers of the possibility of resisting organization. If the organization game is reached, managers may decide to fight organization, and their ability to do so will determine $w^{u}$, and $c$.
} 
2. Multiple Equilibria. $\left(v_{L}-\left(q w_{H}^{u}+(1-q) w_{L}^{u}-c\right) \geq v_{L}^{u}-w_{L}^{u}\right)$. The ex ante probability of organization in a separating equilibrium is as described above, and, in a pooling equilibrium the proof of proposition 4 shows that it is

$$
u_{p} \leq \frac{(1-q)\left(w_{H}^{u}-w_{L}^{u}\right)}{(1-q)\left(w_{H}^{u}-w_{L}^{u}\right)+v_{H}-v_{H}^{u}+c}
$$

Inspection of the above expressions shows that, for a given regime, increases in $\left(w_{H}^{u}-w_{L}^{u}\right)$, and decreases in $c,\left(v_{H}-v_{H}^{u}\right)$, and $\left(v_{L}-v_{L}^{u}\right)$ increase the bounds of the possible values of the probability of organization. Moreover, these changes may also lead to a switch from regime 1 to regime 2. This switch reduces the lower bound of the interval of possible values of the probability of organization (from $\frac{(1-q)\left(w_{H}^{u}-w_{L}^{u}\right)}{\left(w_{H}^{u}-w_{L}^{u}\right)+v_{H}-v_{H}^{u}+c}$ to 0 ), and it is easy to check that it also reduces the upper bound if Assumption Sorting is slightly strengthened to require $v_{H}-v_{H}^{u}+(1-q) w_{H}^{u}>$ $v_{L}-v_{L}^{u}+(1-q) w_{L}^{u}$. Despite the fact that the multiplicity of equilibria precludes precise comparative statics results, we can thus say that, if any of the above parameter changes affects the set of possible equilibria, it will either add new equilibria involving a higher probability of organization, or eliminate equilibria with lower probability of organization than the remaining ones. $^{28}$ Therefore, the probability of organization will increase (in this sense) if costs of union organization or the efficiency cost of unions fall, or if the spread of the distribution of union negotiated wages widens.

\section{c Union Effects on Profits}

Assuming that $v^{u} \leq v$ ensures that in the model unions reduce profits. If we allowed $v^{u}$ to be larger than $v$, however, unions could reduce or increase profits. Therefore, if unions can enhance efficiency the model cannot predict a priori their effect on profits.

More interestingly, the model implies that conventional estimates of this effect may be biased. Propositions 4, and 5 imply that L firms are overrepresented among unionized firms, while $\mathrm{H}$ firms are overrepresented among nonunion firms. Therefore, the difference between the average profits of union and nonunion firms overestimates the (average) union effect. In the context of conventional OLS estimation, propositions 4, and 5 imply that if we estimate a profit equation with a union status dummy as a regressor, this variable will be negatively correlated with the error term (those firms with lower unobservable profitability are more likely to become organized). Therefore, the OLS coefficient for union status will overestimate (in absolute value) the negative effect of unionization on profits (or underestimate its positive effect).

The model also implies that the use of longitudinal data may not ameliorate the problem, as changes in union status are likely to be caused by changes in unobserved profitability. Therefore the assumption of fixed firm effects cannot be used to identify the effect of unions on profits. The

\footnotetext{
${ }^{28}$ See Ruiz-Verdú (2000) for a formal definition of the concepts of nonincreasing and nondecreasing in this context, and for a derivation of the comparative statics results when equilibria in which firms play mixed strategies are allowed too.
} 
role of organization costs in the determination of unionization, however, suggests that finding an instrument that is likely to be correlated with the costs of organization (e.g. state laws, or demographic or attitudinal characteristics) but not with firm profitability could be a way to control for the above bias.

\section{d Union-Nonunion Wage Gap}

If we let $W G$ be the OLS estimate of the union wage gap (that is, the difference between average union and nonunion wages among ex ante identical firms), propositions 4, and 5 imply that:

Corollary $1 W G$ is increasing in $c,\left(v_{H}-v_{H}^{u}\right)$, and $\left(v_{L}-v_{L}^{u}\right)$, and decreasing in $\left(w_{H}^{u}-w_{L}^{u}\right)$. Therefore $W G$ and the probability of organization will be negatively correlated.

Therefore, the argument that a greater wage gap should be associated with an increased probability of organization does not hold true once the determination of both wages and unionization are studied simultaneously. Moreover, as with the probability of organization, there is no a priori relationship between ex ante expected rents and the wage gap. Therefore, without further knowledge of the shape of the distribution of rents, we cannot conclude that the wage gap should be higher in a more profitable industry (that is, one with higher ex ante expected rents).

Propositions 4, and 5 also imply that the OLS estimation of the effect of unionization on wages will be biased due to firm selection into the union sector. In this case, the bias will have a negative sign, as high-wage firms ( $\mathrm{H}$ firms) are more likely to remain nonunion. ${ }^{29}$ However, note that this does not imply that OLS estimates are necessarily biased downwards, as there might be other sources of bias associated with unobservable worker or job characteristics. These sources of bias have not been contemplated in this paper (where all workers are identical), and are likely to operate in the opposite direction (with, say, workers with higher unobservable skills more likely to hold higher paying union jobs).

\section{Employment Determination Under Asymmetric Information}

Asymmetric information can lead to inefficient unionization because less profitable firms trigger it to reveal their type. If firms set employment as well as wages, however, L firms may have another instrument to signal their type: If labor is less productive in those firms, they can reduce employment to dissuade $\mathrm{H}$ firms, for which the reduction would be more costly, from imitating them. If L firms found it profitable to signal their type in this way, then at least some firms would hire less workers than predicted by the complete information model. Moreover, the availability of a signal other than unionization may also imply that inefficient organization

\footnotetext{
${ }^{29}$ If we cannot control for all observable firm characteristics, this bias could be reduced, or even reversed if, in an industry in which unionization takes place with positive probability, there are firms with rents so low that unionization is not ex ante profitable for any wage offer. In this case, this low-wage firms will be overrepresented within the nonunion firms.
} 
is not possible even under asymmetric information. This section addresses these questions by analyzing employment determination in the presence of asymmetric information.

The structure of the model is the same as in the previous section, except that now firms also decide how many workers to hire each period. As in the previous section, firms learn their profitability at the beginning of the second period, before making their wage and employment choices for that period. There are two types of firms, which differ in their second-period revenue functions, which are $R_{H}$ for $\mathrm{H}$ firms, and $R_{L}$ for $\mathrm{L}$ firms, with $R_{H}(l)>R_{L}(l)$ for all $l>0$, and $R_{H}^{\prime}(l)>R_{L}^{\prime}(l)$, for all $l \geq 0$. The ex ante probability of a firm being of type $\mathrm{H}$ is $q$, assumed to be common knowledge.

Workers do not observe $R$. After observing $(w, l)$ they update their beliefs about the firm's type, which can be summarized by $q(w, l)$, the probability that workers assign to the firm being of type H. These beliefs and the expected bargaining outcome at each type of firm determine workers' expected utility from unionization. As in the previous section, it is assumed that the union is able to observe the firm's type, so that the expected bargaining outcome for each firm type is determined as in section III. These bargaining outcomes satisfy the property that unions extract larger rents from more profitable firms. ${ }^{30}$

Lemma 3 Let $\left(l_{i}^{u}(l), w_{i}^{u}(l)\right)(i \in\{L, H\})$ be the bargaining outcome at a firm of type $i$ for a given $l$. Then

$$
l_{H}^{u}(l)\left(w_{H}^{u}(l)-\bar{w}\right) \geq l_{L}^{u}(l)\left(w_{L}^{u}(l)-\bar{w}\right)
$$

This result implies that, under complete information, $\mathrm{H}$ firms need to pay more to avoid unionization:

Corollary 2 Let $w_{H}(l)=\frac{l_{H}^{u}(l)}{l}\left(w_{H}^{u}(l)-\bar{w}\right)+\bar{w}, w_{L}(l)=\frac{l_{L}^{u}(l)}{l}\left(w_{L}^{u}(l)-\bar{w}\right)+\bar{w}$, and $w(l)=$ $q(w, l) w_{H}(l)+(1-q(w, l)) w_{L}(l)$. Then, for any $q(w, l), w_{L}(l) \leq w_{H}(l)$, and $w(l) \leq w_{H}(l)$.

In what follows, I will abstract from first-period considerations, and focus on how the threat of unionization affects the desired level of employment in the second period. Therefore, firms are supposed to choose employment unrestricted by their initial choice of employment, $l_{0}$. As in section III, this omission does not alter the nature of the results.

To reduce the multiplicity of equilibria, in this section equilibria will be required to satisfy the Cho and Kreps Intuitive Criterion (Cho and Kreps (1987)). This criterion requires outof-equilibrium beliefs to assign probability zero to players choosing strategies that are certain to yield a payoff lower than their equilibrium payoff, and that, on the other hand, could be

\footnotetext{
${ }^{30} \mathrm{As}$ in section III, all results generalize to any bargaining process satisfying this property, the aforementioned monotonicity assumption, and such that $l^{u}(l)$, and $w^{u}(l)$ are continuous functions.
} 
preferred by other players to their respective equilibrium payoffs. ${ }^{31}$ Requiring equilibria to satisfy the Intuitive Criterion rules out all pooling equilibria.

Proposition 6 There are no pooling equilibria.

At a pooling equilibrium, the pooling wage $w_{p}$ is greater than $w_{L}\left(l_{p}\right)$, where $l_{p}$ is the pooling level of employment. Therefore, it is possible to increase profits by decreasing employment, if by doing so workers were led to believe that the firm is of type L. Now, the fact that $R_{H}^{\prime}>R_{L}^{\prime}$ implies that a given reduction in employment lowers H's revenues more than L's revenues. Thus, it is possible to find an $l<l_{p}$ such that $\mathrm{H}$ prefers the equilibrium play to $\left(w_{L}(l), l\right)$, while $\mathrm{L}$ prefers $\left(w_{L}(l), l\right)$ to $\left(w_{p}, l_{p}\right)$, which violates the Intuitive Criterion.

Let $\left(w_{i}^{*}, l_{i}^{*}\right)$ be the choice of a firm of type $i(i \in\{L, H\})$ under complete information, computed in proposition 3. The next proposition shows that, at any equilibrium in which firms reveal their type, $\mathrm{H}$ firms will set $\left(w_{H}^{*}, l_{L}^{*}\right)$

Proposition 7 At any fully separating equilibrium, $H$ firms avoid organization with certainty, and set $\left(w_{H}, l_{H}\right)=\left(w_{H}^{*}, l_{H}^{*}\right)$.

This result follows directly from corollary 2. Independently of workers' beliefs, $\mathrm{H}$ firms need not pay more than $w_{H}^{*}$ to avoid unionization if they select $l_{H}^{*}$. Therefore they can always do better by choosing their complete information optimum rather than any other $(w, l)$ pair that revealed their type.

Lemma 4 Let $\bar{l}<l_{H}^{*}$ be defined by: $R_{H}(\bar{l})-w_{L}(\bar{l}) \bar{l}=R_{H}\left(l_{H}^{*}\right)-w_{H}^{*} l_{H}^{*}$. Then $R_{H}\left(l_{H}^{*}\right)-w_{H}^{*} l_{H}^{*}>$ $R_{H}(l)-w_{L}(l) l$ for any $l<\bar{l}$.

That is, if $l<\bar{l}$ then an $\mathrm{H}$ firm prefers to set $\left(w_{H}^{*}, l_{H}^{*}\right)$ and pass as $\mathrm{H}$ than to set $\left(w_{L}(l), l\right)$, and convince workers it is of type $\mathrm{L}$.

Proposition 8 If $\bar{l}>l_{L}^{*}$ then at any fully separating equilibrium, $l_{L}=l_{L}^{*}$ and organization is avoided with certainty.

The interpretation of the proposition is straightforward. If the differences between firms are such that $\mathrm{H}$ firms could not possibly find it profitable to imitate the optimal behavior of $\mathrm{L}$ firms, then the presence of asymmetric information is irrelevant: each firm behaves exactly as if there were no informational asymmetries. In this case, the overemployment results found for the perfect information case would extend to all types of firms under asymmetric information.

Proposition 9 If $\bar{l} \leq l_{L}^{*}$, and

$$
R_{L}(\bar{l})-w_{L}(\bar{l}) \bar{l} \geq R_{L}\left(l_{L}^{u *}\right)-w_{L}^{u *} l_{L}^{u *},
$$

\footnotetext{
${ }^{31}$ All results below regarding fully separating equilibria would still hold if we imposed the weaker requirement that workers do not assign a positive probability to firms playing strictly dominated strategies.
} 
i. There exist fully separating equilibria at which $\left(w_{L}, l_{L}\right)=\left(w_{L}(\bar{l}), \bar{l}\right)$ and $o\left(w_{L}, l_{L}\right)=0$.

ii. There exist no other fully separating equilibria at which $o\left(w_{L}, l_{L}\right)=0$.

ii. There exist fully separating equilibria with $l_{L}>\bar{l}$ and $o\left(w_{L}, l_{L}\right)>0$.

Proposition 10 If $\bar{l} \leq l_{L}^{*}$, and

$$
R_{L}(\bar{l})-w_{L}(\bar{l}) \bar{l}<R_{L}\left(l_{L}^{u *}\right)-w_{L}^{u *} l_{L}^{u *}
$$

$i$. There exist fully separating equilibria at which L firms become organized with certainty

ii. There do not exist fully separating equilibria at which L firms avoid organization with certainty.

iii. There exist fully separating equilibria at which $o\left(w_{L}, l_{L}\right) \in(0,1)$.

If $\bar{l} \leq l_{L}^{*}$, H firms would like to imitate $\mathrm{L}$ firms if the latter were behaving as in the complete information case. Therefore, L firms will alter their behavior to reveal their type to workers. Because the marginal productivity of labor is lower in these firms, they may signal their type by reducing employment to levels for which imitation would not be profitable for $\mathrm{H}$ firms. On the other hand, since it is also less costly for L firms to endure unionization, they may trigger organization to reveal their type, as in the previous section. If condition (2) holds, L firms will signal their type by reducing employment rather than by becoming organized. ${ }^{32}$ Therefore, the overemployment effect of the threat of unionization will be reduced in L firms, and could even be reversed. If $l_{L}^{u *}<l_{L c}$ (where $l_{L c}$ is the level of employment that would result if $\mathrm{L}$ firms acquired their labor input in a perfectly competitive labor market), then it is possible that $l_{L}<l_{L c}$. However, there is a limit to this reduction in employment, as condition (2) ensures that $\bar{l}$ cannot be much lower than $l_{L}^{u *}$ (if organization costs were zero, condition (2) would guarantee that $\left.l_{L} \geq l_{L}^{u *}\right)$. On the other hand, if condition 3 holds, the level of employment necessary to avoid being imitated by $\mathrm{H}$ firms is so low, that $\mathrm{L}$ firms prefer to trigger unionization to signal their type. Therefore, the result in propositions 4 , and 5 is robust: less profitable firms are more likely to become unionized.

Obtaining comparative statics results in this case is not possible without imposing specific functional forms for the revenue and cost functions. However, it can be easily checked that, at least if we restrict our attention to pure strategy equilibria (which, as mentioned in the previous footnote, are the only ones in which beliefs are monotonic), an upward shift in $C$ will make organization less likely and increase the empirical wage gap, as in the previous section. Therefore, we can expect the negative relationship between the rate of organization and the wage gap derived in the previous section to hold here as well.

\footnotetext{
${ }^{32}$ Even if condition (2) holds, equilibria with a positive probability of organization may exist, in which L firms use both signals at once. However, equilibria of this form have the property that workers' beliefs are not monotonic: they require workers to believe that a firm is of type $\mathrm{L}$ if it offers $\left(w_{L}\left(l_{L}\right), l_{L}\right)$, while believing that any other $(w, l)$ such that $w=w_{L}(l)$ and $l \in\left[\bar{l}, l_{L}\right)$ could have been chosen by a firm of type H. This feature makes them less compelling predictions than the pure strategy equilibria.
} 
Although the model is static and partial equilibrium, it suggests a potential cyclical implication of the threat of unionization in an uncertain environment. If uncertainty has an aggregate component, and managers have better information about the realization of uncertainty, the negative effect of an adverse shock to firms' profitability will be amplified by the need to convince workers that the negative aggregate shock has indeed occurred. ${ }^{33}$ The threat of unionization may thus lead to greater employment responses to shocks than those implied by a competitive labor market, a possibility that should be explored further.

\section{Empirical Evidence}

In this section, I make use of the empirical literature on the determinants and effects of unionization to provide a tentative assessment of the model's predictive performance. However, one should keep in mind that the relationship between the model's variables and the variables estimated in this literature is, generally, far from perfect (for example, while I have looked at the average wage gap among ex ante identical firms, the data can, at best, offer reliable estimates at the industry level), and that, except for the paper by Ruback and Zimmerman discussed below, the studies reviewed do not provide explicit tests of the predictions of the model.

\section{A Joint behavior of union density and the wage gap}

Since the early 1970s, the U.S. has experienced a large decline in the proportion of private sector workers who belong to unions. On the other hand, as Figure 1 shows, the union wage premium seems to have remained constant, or even trended upwards. ${ }^{34}$ In fact, although his results are only exploratory, Freeman (1986) finds a negative correlation between the aggregate wage gap and new unionization. Moreover, a clearer negative correlation emerges when the analysis is done at the industry level. ${ }^{35}$ Finally, data from 1930-1974, although less reliable than more recent micro-data, also point in the direction of a negative correlation between union density and the wage gap, or at least of an absence of a positive correlation. In particular, those periods in which the greatest increases in union density took place were accompanied by lower union wage gaps than periods of union decline or moderate growth. ${ }^{36}$

\footnotetext{
${ }^{33}$ This possibility was first analyzed for the case in which firms and workers agree to implicit insurance contracts (Grossman and Hart (1981), Grossman and Hart (1983), Grossman, Hart, and Maskin (1983), Azariadis (1983)). Acemoglu (1995), and Kennan (2000) have also studied the cyclical effects of asymmetric information when workers and firms bargain over the wage.

${ }^{34}$ A similar pattern can be observed in the U.K. See Blanchflower (1997), Andrews, Bell, and Upward (1998), Stewart (1991), Stewart (1995). The studies reviewed, using different datasets and methods, do not agree on the sign and size of the change in the wage gap. One can, however, conclude that no significant decline in the wage gap has taken place.

${ }^{35}$ See Linneman and Wachter (1986), Linneman, Wachter, and Carter (1990). The latter paper finds a negative coefficient for the union wage gap in union density equations for all major industries, except construction and government, for the years 1973-86.

${ }^{36}$ See, Pencavel (1991), pp. 26-30.
} 
The time-series behavior of union density and the wage gap thus seems consistent with the predictions of this paper, while more difficult to reconcile with theories that explain the changes in union density as a result of changes in expected wage gains from organization. The model's predictions are also consistent with the cross-sectional pattern of union density and the union wage premium in the U.S.. Inspection of this pattern shows a negative correlation between the two variables when comparing regions (the U.S. South vs. other regions, or rural vs. urban areas), sectors (the private vs. the public sector), or establishments of different size (with smaller establishments being characterized by a smaller union density and a higher wage gap), at least for manufacturing. ${ }^{37}$ The same pattern seems to hold when comparing different countries, even if we limit the comparison to relatively similar countries like the U.S., Canada and the U.K.. Especially interesting is the case of the U.S. and Canada, given their relative similarity (also in what respects to collective bargaining regulation.) The higher union density in Canada is not accompanied by higher wage premia.

\section{B Determinants of unionization}

Although I am not aware of studies specifically aimed at testing the influence of profitability on the probability of organization, two studies, using different datasets and methodologies, find either no or negative correlation between firm growth (Bronars and Deere (1993)) or profitability (Bronfenbrenner (1997)) and unionization. These results do not provide conclusive evidence for or against the predictions of this paper (which, without further controls, could only be conclusively falsified by a strong positive effect of profitability on the probability of organization), but they certainly cast doubt on the common rent-seeking view that unions will organize more profitable establishments.

With respect to the effect that potential efficiency consequences of unionization have on the probability of organization, Duncan and Stafford (1980) provide evidence that unionization is associated with working conditions "which require interdependent worker behavior as part of the production process" (ibid. p. 369), such as working with machines, work pace, or inflexible hours of work. In the authors' interpretation, these working conditions make collective representation efficient, thus supporting the relevance of efficiency explanations of union incidence. On the other hand, the evidence on the productivity effects of unions is mixed, although Freeman (2000) reports that a majority of studies find a positive productivity effect.

\footnotetext{
${ }^{37}$ This description is based on Lewis's comprehensive survey of empirical measures of the wage gap (Lewis (1986)). I am not aware of any more recent study showing correlations of a different sign. Note that we have not presented any result on how the wage gap varies with the extent of unionism in an industry, which would be a more direct test of the theory. The reason is that results seem to be extremely sensitive to the choice of variable measuring the extent of unionism, and to pick up the effect of omitted variables more than effects of unionism. For a discussion, see Lewis (1986).
} 


\section{Asymmetric information and unionization}

The model predicts that firms with negative private information about their profit prospects will be more likely to become organized. Ruback and Zimmerman (1984) provide an ideal test of this prediction in a study written with the objective of estimating the effect of unions on profits. Using a sample of large publicly traded firms in which at least one unionization attempt takes place during the period 1962-1980, the authors computed abnormal stock returns for the month in which the union petitions for an election, and the month in which the election outcome is certified. If the election petition conveys no information about the firm's type, the stock market price of a firm where a union election is petitioned should decrease at the date of the petition (since a petition is associated with a greater probability of organization), but should go up, at least partially, if the union loses the election. If, however, there is a signaling effect, the positive impact of a union loss on the stock price should be smaller, since, although the union loss implies higher future profits (driving the price up), the negative information conveyed by the unionization attempt implies that profit expectations are lower after the union loss than before the election petition. Ruback and Zimmerman report that, in the month of an election petition, abnormal returns are negative and statistically significant both in those firms in which the unionization attempt will end up being successful, and in those where it will lead to a union loss. Although the negative abnormal returns are smaller in the latter group of firms, the difference is not statistically significant. In the month in which the election outcome is certified, abnormal returns are negative in firms where the union wins and in those in which the union loses, although in both cases they are not significantly different from zero. That is, the news of a union loss does not significantly increase profit expectations. This result provides firm support for the asymmetric information explanation of unionization. ${ }^{38}$

Bronars and Deere (1993) also report that GNP growth was significantly above average before periods of union recognition activity, and significantly below average after those periods, a finding also consistent with the asymmetric information explanation for unionization.

\section{The effect of unions on nonunion wages}

When asked about the motivation for their wage and employment policies, employers declare to take into account the expected influence of those policies on workers' incentives to unionize, at least when they perceive unionization as probable (Rees and Schultz (1970), Foulkes (1980)). In particular, the employers questioned in those studies set high wages to keep unions at bay. In line with these findings, most cross-sectional studies estimate a positive effect of union density on nonunion wages (see Neumark and Wachter (1995) for a review of these studies). Insofar as

\footnotetext{
${ }^{38}$ It could be argued that this may be due to investors' anticipation of the election result. But the fact that those firms where the union will lose the election experience significant negative abnormal returns the month of the election petition (and not significantly different from the abnormal returns of firms in which the union will win) suggests that investors' anticipation is not complete.
} 
the variation in union density is caused by differences in organization costs, the model in this paper would yield the same prediction.

However, cross-sectional studies have been criticized for not controlling for unmeasured industry characteristics associated with different degrees of unionization. If unionization were more likely in industries that would have paid higher wages in any case, cross-sectional estimates could be just capturing this fact. Neumark and Wachter (1995) used panel data to control for unmeasured time-invariant industry characteristics, and finds a negative effect of changes in union density on nonunion inter-industry wage differentials. However, their study is subject to a similar criticism than the one they raise for the cross-sectional studies, as the changes in industry conditions that lead to changes in union density are likely to be correlated with nonunion wages as well. Moreover, when they estimate the effect of local (at the SMSA ${ }^{39}$ level) union density on nonunion wages, they find a significant positive effect of union density on inter-SMSA nonunion wage differentials. Since displaced workers are much more likely to change industries than to move to a different city or county (Herz (1990)), this finding provides strong evidence against the view that unionization lowers the wages of nonunion workers by increasing the supply of labor to the nonunion sector.

In the study that most closely approximates the ideal experiment to test the model's predictions, Ichniowski, Freeman, and Lauer (1989) trace the effects of changes in state collective bargaining laws on union and nonunion police compensation. They find that changes in bargaining laws that make it easier for public sector employees to bargain collectively increase union density, and increase the compensation of both union and nonunion police. Unfortunately, these results refer only to a particular class of public sector workers, so that no general conclusions can be extracted.

\section{Suggestions for Further Research}

The analysis in this paper provides a first step in the understanding of the operation of partially unionized labor markets, and the determinants of unionization. This section outlines some directions along which this research can be fruitfully extended.

First, studying the consequences of the model for market equilibrium would allow us to determine the net effect of different parameter changes on wages, aggregate employment, and union membership. The latter may be especially important because several variables in the model are likely to depend on aggregate union membership. For example, costs of organization may depend on the number of unionized workers in an industry. Moreover, we must take these externalities into consideration if we are to compare the performance of different systems of collective bargaining (for example, decentralized versus industry-level or regional bargaining), as one of the main dimensions along which these systems vary is the degree to which labor market

\footnotetext{
${ }^{39}$ Standard Metropolitan Statistical Area.
} 
participants internalize organization and bargaining externalities. Although the model indicates that increases in union density are likely to be associated with an improvement of the welfare of nonunion workers, the analysis of market equilibrium is also necessary to assess possible equilibrium effects that may alter this prediction. Finally, since it is difficult to obtain reliable measures below the industry level for most of the variables of interest, aggregate predictions should also be easier to bring to the data.

Second, an explicitly dynamic extension of the model would clarify the model's cyclical implications, and allow us to obtain predictions that can be more readily tested using timeseries data. It would also shed light on the factors behind the development of unionism in the U.S. private sector, characterized by a rapid rise in union density in the period between the Great Depression and the mid 1950s, and by a monotonic decline ever since. To understand this development, the model in this paper indicates that special attention should be paid to the evolution of the costs of organization to workers.

Third, although the review of the evidence conducted in this paper is supportive of the predictions of the model, empirical work specifically aimed at testing these predictions, and those generated by the extensions outlined above, is required. In particular, it would be especially fruitful to obtain good measures of the costs of organization to workers, and their relation to wages, employment and union membership.

Lastly, more sophisticated contract forms should also be considered. The model restricts contracts to be noncontingent, while suggesting that efficiency gains could be possible if compensation were made to depend on potentially verifiable variables like profits or employment. Similarly, implicit contracts which made compensation contingent on firm profitability could be, in principle, sustainable if firms and workers interact repeatedly. Studying possible private responses to the inefficiency caused by asymmetric information is also necessary to evaluate the potential for efficiency-enhancing policy intervention. In particular, it would be worth investigating whether measures aimed at reducing the informational asymmetries between firms and workers, such as, say, compulsory worker representation on company boards (even if lacking any decision rights), or information disclosure requirements could alleviate this inefficiency.

\section{Conclusion}

Nonunion employers in a partially unionized industry are not likely to behave as described by standard competitive models. Rather than taking wages as given, they will set wages and employment strategically to ensure that their workers do not organize. In this paper, I have shown that as a result, labor market outcomes will depart significantly from those derived from models in which the nonunion sector is assumed to operate competitively.

In particular, nonunion wages will be set above the competitive level to eliminate workers' incentives to organize. Despite this increase in the average cost of labor, employment will 
generally not fall, as nonunion firms have the incentive to overemploy to reduce the average rents that workers can expect to obtain if they organize. If employers are better informed than workers about profitability, however, less profitable firms may have an even stronger incentive to lay off workers, if by doing so they can convince the remaining employees of their bad profit outlook, thus persuading them to moderate their wage demands. Although its macroeconomic consequences are yet to be derived explicitly, the model suggests that the effect on employment of negative shocks could be amplified by firms' recourse to layoffs as a device to lower wage demands and avoid unionization.

By explicitly modelling employer behavior towards unionization, this paper has also provided a theory of the incidence of unionism. The interest of such a theory is twofold. On the one hand, it offers a new framework to study the causes and consequences of the decline of U.S. unionism in the last two decades. Moreover, unlike one-sided theories, which take either wages or union density as given, this framework is able to offer predictions about the joint behavior of these variables. Of special interest is the prediction that union density and the union wage premium will tend to be negatively correlated, which seems to fit the pattern observed in the U.S.. This pattern is, however, difficult to rationalize by theories of union formation that take the wage premium as given.

On the other hand, a theory of the simultaneous determination of unionization, wages and employment addresses the key issue in the empirical literature examining the effects of labor unions, namely the nonrandom determination of union status. According to the model, the probability of union organization does not depend on observable firm characteristics not directly related to the costs of organization to workers, or the potential effect of unions on total rents. It follows that observable measures of profitability are not likely to be informative to predict union organization. In contrast, unobservable profit prospects play a large role in the determination of union status. That is, unionization is likely to be correlated with unobservable firm characteristics, which, at the same time, have a direct effect on firm performance. Therefore, the model predicts that OLS estimates of the effects of unionization will be biased. Against the often held assumption that unions will organize the (unobservably) more profitable firms, the model predicts that organization will be more likely in (unobservably) less profitable firms, and thus pins down the sign of the estimation bias. Apart from cautioning us about the existence and sign of this bias, the model also has implications concerning possible remedies. In particular, it does not favor the use of longitudinal data to identify union effects, as fixed firm characteristics, as long as they are observable by workers, will be unrelated to changes in union status. The role of organization costs in the determination of union status, however, suggests that factors unrelated to firm performance but correlated with these costs (like changes in the legal environment regulating collective bargaining, or differences in workers' attitudes towards unions) may be used as instruments for unionization. 


\section{Appendix}

Proof of Lemma 1. Let problem (A) be: $\max _{l^{u}} U_{A}\left(l^{u}\right)=l^{u}\left(R^{\prime}\left(l^{u}\right)-\bar{w}\right)$. If $U_{A}$ is strictly concave, then problem (A) has at most one solution, $l^{u *}$, and, assuming $R^{\prime}(0)>\bar{w}$, and $R^{\prime}(l)<$ $\bar{w}$ for $l$ large enough, $l^{u *}>0$ is given by $R^{\prime}\left(l^{u *}\right)=\bar{w}+l^{u *} R^{\prime \prime}\left(l^{u *}\right)>\bar{w}$. Therefore, $l^{u *}<l_{c}$. Since $U_{A}^{\prime \prime}=2 R^{\prime \prime}+l^{u} R^{\prime \prime \prime}$, concavity of $R^{\prime}$ guarantees concavity of $U_{A}$. Let $w^{u *}=R^{\prime}\left(l^{u *}\right)>\bar{w}$.

Now, the union solves:

$$
\begin{aligned}
\max _{l^{u}, w^{u}} & l^{u}\left(w^{u}-\bar{w}\right) \\
\text { s.t. } & l^{u}=\arg \max \left\{R\left(l^{u}\right)-w^{u} l^{u}, \text { for } l^{u} \leq l\right\}
\end{aligned}
$$

It cannot be the case that $w^{u}<R^{\prime}(l)$, since in that case $l^{u}=l$, and the union would be better off setting $w^{u}=R^{\prime}(l)$, which would increase the wage without lowering employment. Therefore $w^{u} \geq R^{\prime}(l)$ for all $l$. It follows that $l^{u}$ will satisfy $R^{\prime}\left(l^{u}\right)=w^{u}$. The problem of the union thus becomes:

$$
\begin{array}{ll}
\max _{l^{u}} & l^{u}\left(R^{\prime}\left(l^{u}\right)-\bar{w}\right) \\
\text { s.t. } & l^{u} \leq l
\end{array}
$$

If $l^{u *}$ is feasible, then it maximizes this problem. Thus $l^{u}(l)=l^{u *}$, for $l \geq l^{u *}$. Now, concavity of $U_{A}$ ensures that the derivative of the maximand is positive for $l<l^{u *} R^{\prime}\left(l^{u *}\right)-\bar{w}-l^{u *} R^{\prime \prime}\left(l^{u *}\right)>$ 0 for $l<l^{u *}$, therefore for $l<l^{u *}, l^{u}(l)=l$. This proves 1$)$, which, together with $l^{u *}<l_{c}$, proves 2). Similarly, 3) follows from 2) and the fact that $w^{u}=R^{\prime}(l)$. Finally, 4) follows from 1) - 3), as $R\left(l^{u}(l)\right)-l^{u}(l) w^{u}(l)=R(l)-l R^{\prime}(l)$ for $l<l^{u *}$, which is increasing in $l$ due to the concavity of $R$, and $R\left(l^{u}(l)\right)-l^{u}(l) w^{u}(l)=R\left(l^{u *}\right)-l^{u *} R^{\prime}\left(l^{u *}\right)$ for $l \geq l^{u *}$.

Proof of Proposition 2. If the firm offers a wage below $w^{*}(l)$, workers form a union and profits are $\Pi_{U}(l)=R\left(l^{u}(l)\right)-w^{u}(l) l^{u}(l)$. If it offers $w^{*}(l)$, and workers accept, profits are:

$$
\begin{aligned}
\Pi(l) & =R(l)-l\left(\frac{l^{u}(l)}{l} w^{u}(l)+\frac{l-l^{u}(l)}{l} \bar{w}-\frac{C(l)}{l}\right) \\
& =R(l)-l^{u}(l) w^{u}(l)+\left(l-l^{u}(l)\right) \bar{w}+C(l)
\end{aligned}
$$

Let $l^{u *}$ be defined as in lemma 1 , so that $R\left(l^{u}(l)\right)-l^{u}(l) w^{u}(l)$ is maximized at $l^{u *}$. Then, if the firm chooses $l=l^{u *}$, the above inequalities imply $\Pi\left(l^{u *}\right)>R\left(l^{u *}\right)-l^{u *} w^{u}\left(l^{u *}\right)=\Pi_{U}\left(l^{u *}\right) \geq$ $\Pi_{U}(l)$, for any $l$. It follows that for the optimal choice of $l, l^{*}, \Pi\left(l^{*}\right) \geq \Pi\left(l^{u *}\right)>\Pi_{U}(l)$, for any $l$. If $l^{u *}$ is not feasible $\left(l^{u *}>l_{0}\right)$, then it is still true that $\Pi_{U}\left(l_{0}\right) \geq \Pi_{U}(l)$, for any $l<l_{0}$, so that $\Pi\left(l^{*}\right) \geq \Pi\left(l_{0}\right)>\Pi_{U}(l)$, for any $l<l_{0}$. 
Proof of Proposition 3. Proposition 2 implies that it is optimal for the firm to avoid organization, so that profits are given by $R(l)-w(l) l$, where

$$
w(l)=\frac{l^{u}(l)}{l}\left(w^{u}(l)-\frac{C(l)}{l}\right)+\frac{l-l^{u}(l)}{l}\left(\bar{w}-\frac{C(l)}{l}\right)
$$

Now, for $l<l^{u *}, l^{u}(l)=l$, so that $w(l)=w^{u}(l)-\frac{C(l)}{l}$, and profits are $R(l)-w^{u}(l) l+C(l)=$ $R\left(l^{u}(l)\right)-w^{u}(l) l^{u}(l)+C(l)$. But from lemma 1 we know that $R\left(l^{u}(l)\right)-w^{u}(l) l^{u}(l)$ is increasing in $l$ for $l<l^{u *}$. If $C(l)$ is nondecreasing that implies that $l^{*} \geq l^{u *}$.

For $l>l^{u *}, l^{u}(l)=l^{u *}$, and $w^{u}(l)=w^{u *}$, so that $(w(l) l)=l^{u *} w^{u *}+\left(l-l^{u *}\right) \bar{w}-C(l)$. Therefore $\Pi^{\prime}(l)=R^{\prime}(l)-(w(l) l)^{\prime}=R^{\prime}(l)-\bar{w}+C^{\prime}(l)$. It follows that for $l<l_{c}, \Pi^{\prime}(l)>0$, and $l^{*} \geq l_{c}$. $\Pi^{\prime}\left(l_{c}\right)=0$ only if $C^{\prime}\left(l_{c}\right)=0$. If $C^{\prime}\left(l_{c}\right)>0$, then $\Pi^{\prime}\left(l_{c}\right)>0$, so that $l^{*}>l_{c}$.

Proof of Proposition 4. 1) At a separating equilibrium, $\rho(w)=1$ for every $w \in S_{H}$. Thus, any $w \in S_{H}$ such that $w<w_{H}^{u}-c$ cannot be optimal, as shown in Lemma 1. Similarly, $w>w_{H}^{u}-c$ cannot be optimal either, as it is always better to offer $w-\varepsilon>w_{H}^{u}-c$. Therefore, it has to be the case that $S_{H}=\left\{w_{H}^{u}-c\right\}$, and $o\left(w_{H}^{u}-c\right)=0$, as if $o\left(w_{H}^{u}-c\right)>0$, it would be better to offer $w_{H}^{u}-c+\varepsilon$, for $\varepsilon>0$ small enough.

2) $\forall w<w_{H}^{u}-c, \rho(w) w_{H}^{u}+(1-\rho(w)) w_{L}^{u}-c \geq w$. Otherwise $w_{H}^{u}-c$ would not be optimal for the $\mathrm{H}$ firm. In particular, if $w \in S_{L}, w_{L}^{u}-c \geq w, o(w)>0$, and $o(w)\left(v_{H}^{u}-w_{H}^{u}\right)+(1-$ $o(w))\left(v_{H}-w\right) \leq v_{H}-w_{H}^{u}+c$, for the $\mathrm{H}$ firm not to imitate the $\mathrm{L}$ firm.

3) Now, given 1) and 2), for an $\mathrm{L}$ firm not to deviate and imitate an $\mathrm{H}$ firm, it has to be the case that, for any $w \in S_{L}, o(w)\left(v_{L}^{u}-w_{L}^{u}\right)+(1-o)\left(v_{L}-w\right) \geq v_{L}-w_{H}^{u}+c$. For $w<w_{L}^{u}-c$, $o(w)=1$, so that if $w<w_{L}^{u}-c$ and $w \in S_{L}$, it must be the case that $v_{L}^{u}-w_{L}^{u} \geq v_{L}-w_{H}^{u}+c$. If $w=w_{L}^{u}-c$, workers may randomize, but if they do, the above inequality requires $o(w) \leq \frac{w_{H}^{u}-w_{L}^{u}}{v_{L}-v_{L}^{u}+c}$ for $\mathrm{L}$ firms not to imitate high-value ones. Note that, if $v_{L}^{u}-w_{L}^{u} \geq v_{L}-w_{H}^{u}+c$, then $o(w)$ can be 1 for $w \in S_{L}$.

2 ), and 3) thus imply that, if workers play mixed strategies on the equilibrium path

$$
\frac{w_{H}^{u}-w_{L}^{u}}{v_{H}-v_{H}^{u}+c+w_{H}^{u}-w_{L}^{u}} \leq o\left(w_{L}^{u}-c\right) \leq \frac{w_{H}^{u}-w_{L}^{u}}{v_{L}-v_{L}^{u}+c},
$$

which can hold only if Assumption ( $S C$ ) holds.

Now, Assumption $(S C)$ is also sufficient for the existence of separating equilibria, as we can always find beliefs that support such equilibria. For example, if $\rho(w)=1$ for all $w<w_{H}$ such that $w \notin S_{L}$, then the above equilibrium can be supported, and part i. is proven.

Part ii. follows from 1), as no fully separating separating equilibrium can exist in which $\mathrm{H}$ firms get organized with positive probability. 
Proof of Proposition 5. First note that, at any pooling equilibrium, firms play pure strategies. To see this, suppose that firms randomize between $w$ and $w^{\prime}$. For this to be the case, both types of firms must be indifferent between playing $w$ and $w^{\prime}$ :

$$
\begin{gathered}
o(w)\left(v_{H}^{u}-w_{H}^{u}\right)+(1-o(w))\left(v_{H}-w\right)= \\
o\left(w^{\prime}\right)\left(v_{H}^{u}-w_{H}^{u}\right)+\left(1-o\left(w^{\prime}\right)\right)\left(v_{H}-w^{\prime}\right),
\end{gathered}
$$

and

$$
\begin{aligned}
& o(w)\left(v_{L}^{u}-w_{L}^{u}\right)+(1-o(w))\left(v_{L}-w\right)= \\
& o\left(w^{\prime}\right)\left(v_{L}^{u}-w_{L}^{u}\right)+\left(1-o\left(w^{\prime}\right)\right)\left(v_{L}-w^{\prime}\right)
\end{aligned}
$$

The previous two equations form a system of linear equations with $o(w)$ and $o\left(w^{\prime}\right)$ as unknowns. It can be easily checked that the two equations are linearly independent, so that the system has a unique solution. Since $o(w)=1$ and $o\left(w^{\prime}\right)=1$ is a solution of the system, there are no other values of $o(w)$ and $o\left(w^{\prime}\right)$ that satisfy (4) and (5).

Therefore, at any pooling equilibrium, both types of firms offer the same wage $w_{p}$. From lemma 2 , we know that $o\left(w_{p}\right)<1$, so that $w_{p} \geq q w_{H}^{u}+(1-q) w_{L}^{u}-c$.

Now, for $\mathrm{L}$ firms not to trigger organization, we need

$$
o\left(w_{p}\right)\left(v_{L}^{u}-w_{L}^{u}\right)+\left(1-o\left(w_{p}\right)\right)\left(v_{L}-q w_{H}^{u}-(1-q) w_{L}^{u}+c\right) \geq v_{L}^{u}-w_{L}^{u}
$$

or $v_{L}-v_{L}^{u}+c \geq q\left(w_{H}^{u}-w_{L}^{u}\right)$. That is, condition (1) must hold, which proves part 2. Note that Assumption (Sorting) guarantees that, if L firms do not want to trigger organization, H firms do not want to do it either.

1. Condition (1) thus guarantees that no firm wants to trigger certain organization. To have an equilibrium with no organization we also need to ensure that there is no other profitable deviation. Clearly, $w>w_{p}$ cannot be such a deviation. For $w<w_{p}$ not to be a profitable deviation, we need $o(w)>0$, i.e. $w \leq \rho(w) w_{H}^{u}+(1-\rho(w)) w_{L}^{u}-c$. Let workers' beliefs be given by $\rho(w)=1$ for all $w \neq w_{p}$. With these beliefs, no type would want to deviate from $w_{p}$. Note that these beliefs would support any equilibrium with $w_{p} \in$ $\left[q w_{H}^{u}+(1-q) w_{L}^{u}-c, \min \left\{v_{L}-v_{L}^{u}+w_{L}^{u}, w_{H}^{u}-c\right\}\right]$. If $w_{p}>v_{L}-v_{L}^{u}+w_{L}^{u}$, L firms would rather trigger organization, and, if $w_{p}>w_{H}^{u}-c, \mathrm{H}$ firms would deviate to $w_{H}^{u}-c+\varepsilon$, for $\varepsilon>0$ small enough. This proves part 1.i.

2. Now, for workers to play $o\left(w_{p}\right) \in(0,1), w_{p}=q w_{H}^{u}+(1-q) w_{L}^{u}-c$. If $\mathrm{H}$ firms are not to avoid organization with certainty,

$$
o\left(w_{p}\right)\left(v_{H}^{u}-w_{H}^{u}\right)+\left(1-o\left(w_{p}\right)\right)\left(v_{H}-q w_{H}^{u}-(1-q) w_{L}^{u}+c\right) \geq v_{H}-w_{H}^{u}+c
$$


which can be rewritten as

$$
\frac{(1-q)\left(w_{H}^{u}-w_{L}^{u}\right)}{(1-q)\left(w_{H}^{u}-w_{L}^{u}\right)+\left(v_{H}-v_{H}^{u}+c\right)} \geq o\left(w_{p}\right)
$$

Inequality (6) also guarantees that $\Pi_{H}\left(w_{p}\right) \geq v_{H}^{u}-w_{H}^{u}$, as it is always better for $\mathrm{H}$ firms to avoid unionization with certainty than to face unionization with certainty, and, given Assumption (Sorting), that $\Pi_{L}\left(w_{p}\right) \geq v_{L}-w_{H}^{u}+c$.

Condition (1) guarantees that no firm wants to trigger certain organization, and (6) that they do not want to deviate to $w_{H}^{u}-c$ either (and they are consistent). Therefore, if workers' beliefs are given by $\rho(w)=1$ for all $w \neq w_{p}$, any deviation involves either certain organization or paying at least $w_{H}^{u}-c$. Thus, no firm wants to deviate from $w_{p}$.

Proof of corollary 1. Let $p_{H}^{n}$ be the proportion of nonunion firms of type $\mathrm{H}$, and $u_{L}$ the proportion of $\mathrm{L}$ firms that are unionized, so that $p_{H}^{n}=\frac{q}{q+(1-q)\left(1-u_{L}\right)}$. Then, at a separating equilibrium, $W G_{s}=w_{L}^{u}-\left(p_{H}^{n}\left(w_{H}^{u}-c\right)+\left(1-p_{H}^{n}\right)\left(w_{L}^{u}-c\right)\right)=c-p_{H}^{n}\left(w_{H}^{u}-w_{L}^{u}\right)$. At a pooling equilibrium, $W G_{p}=\left(q w_{H}^{u}+(1-q) w_{L}^{u}\right)-\left(q w_{H}^{u}+(1-q) w_{L}^{u}-c\right)=c$. It follows that $W G_{p} \geq W G_{s}$, and that $W G_{s}$ is decreasing in $u_{L}$. Reductions in $\left(w_{H}^{u}-w_{L}^{u}\right)$, and increases in $\left(v_{H}-v_{H}^{u}\right)$, and $\left(v_{L}-v_{L}^{u}\right)$ lower $u_{l}$ (thus raising $W G_{s}$ ) and make pooling equilibrium more likely. Therefore, these changes increase $W G$. An increase in $c$ has the same effect through $u_{L}$ and equilibrium selection, and also increases $W G_{s}$ and $W G_{p}$ directly.

Proof of lemma 3. The fact that $R_{H}^{\prime}>R_{L}^{\prime}$ implies that there exists a pair $\left(w^{u}, l^{u}\right)$ on the $R_{H}^{\prime}$ curve such that $w^{u} \geq w_{L}^{u}(l)$, and $l^{u}>l_{L}^{u}(l)$, so that $l^{u}\left(w^{u}-\bar{w}\right)>l_{L}^{u}(l)\left(w_{L}^{u}(l)-\bar{w}\right)$. Therefore, since $\left(l_{H}^{u}(l), w_{H}^{u}(l)\right)$ is preferred to any other $\left(w^{u}, l^{u}\right)$ on $R_{H}^{\prime}, l_{H}^{u}(l)\left(w_{H}^{u}(l)-\bar{w}\right) \geq$ $l^{u}\left(w^{u}-\bar{w}\right)>l_{L}^{u}(l)\left(w_{L}^{u}(l)-\bar{w}\right)$.

Proof of corollary 2. Follows immediately from lemma 3.

Proof of proposition 6. Let $\left(w_{L}, l_{L}\right)=\left(w_{H}, l_{H}\right)=\left(w_{p}, l_{p}\right)$, such that:

$$
\begin{gathered}
R_{H}\left(l_{p}\right)-w_{p} l_{p} \geq R_{H}\left(l_{H}\right)-w_{H} l_{H}, \\
R_{L}\left(l_{p}\right)-w_{p} l_{p} \geq R_{L}\left(l_{M}\right)-w_{H}\left(l_{M}\right) l_{M} \\
R_{L}\left(l_{p}\right)-w_{p} l_{p} \geq R_{L}\left(l_{L}^{u *}\right)-w_{L}^{u *} l_{L}^{u *},
\end{gathered}
$$

and suppose $o\left(w_{p}, l_{p}\right)=0$,

Define $l_{e}<l_{p}$ by $R_{H}\left(l_{p}\right)-w_{p} l_{p}=R_{H}\left(l_{e}\right)-w_{L}\left(l_{e}\right) l_{e}$, so that if $l<l_{e} \mathrm{H}$ prefers the equilibrium play to $\left(w\left(l_{e}\right), l_{e}\right)$ for any beliefs that workers may hold. Therefore, for the equilibrium to satisfy the Intuitive Criterion, it has to be the case that if $l<l_{e}$, then $q\left(w_{L}(l), l\right)=0$. But, in this 
case:

$$
\begin{array}{r}
R_{L}\left(l_{e}\right)-w_{L}\left(l_{e}\right) l_{e}-\left(R_{L}\left(l_{p}\right)-w_{p} l_{p}\right)= \\
R_{L}\left(l_{e}\right)+R_{H}\left(l_{p}\right)-w_{p} l_{p}-R_{H}\left(l_{e}\right)-\left(R_{L}\left(l_{p}\right)-w_{p} l_{p}\right)= \\
\left(R_{H}\left(l_{p}\right)-R_{L}\left(l_{p}\right)\right)-\left(R_{H}\left(l_{e}\right)-R_{L}\left(l_{e}\right)\right)>0
\end{array}
$$

Therefore, there exists a profitable deviation for $\mathrm{L}$, and $\left(w_{L}, l_{L}\right)=\left(w_{H}, l_{H}\right)=\left(w_{p}, l_{p}\right)$ cannot be an equilibrium with $o\left(w_{p}, l_{p}\right)=0$.

The same argument would apply for $o\left(w_{p}, l_{p}\right)>0$, as it would still be the case that for $l_{e}$ as defined above, $\left(w_{L}\left(l_{e}-\epsilon\right), l-\epsilon\right)$ for $\epsilon>0$ small enough is a profitable deviation for L. Partly revealing equilibria could be eliminated in the same way.

Proof of proposition 7. Let $\left(l_{H}, w_{H}\right) \neq\left(l_{H}^{*}, w_{H}^{*}\right)$ be H's equilibrium play. Then, at any fully separating equilibrium, either $w_{H}=w_{H}\left(l_{H}\right)$ or workers organize with positive probability. Now, corollary 2 implies that $R_{H}\left(l_{H}^{*}\right)-w\left(l_{H}^{*}\right) l_{H}^{*} \geq R_{H}\left(l_{H}^{*}\right)-w_{H}\left(l_{H}^{*}\right) l_{H}^{*}$. Therefore, since $l_{H}^{*}$ is the unique optimal $l$ under perfect information, $R_{H}\left(l_{H}^{*}\right)-w_{H}\left(l_{H}^{*}\right) l_{H}^{*}>R_{H}\left(l_{H}^{u}(l)\right)-w_{H}^{u}(l) l_{H}^{u}(l)$, and $R_{H}\left(l_{H}^{*}\right)-w_{H}\left(l_{H}^{*}\right) l_{H}^{*}>R_{H}(l)-w_{H}(l) l$ for all $l$. Choosing $l_{H}^{*}, w_{H}^{*}+\epsilon$, for $\epsilon \geq 0$ small enough, is thus a profitable deviation, so that $\left(l_{H}, w_{H}\right)$ cannot be H's equilibrium play. The same argument would apply if $\mathrm{H}$ randomized at the proposed equilibrium play.

Proof of lemma 4. Existence of $\bar{l}$ follows from $R_{H}(0)=0$ and the continuity of $R_{H}$ and $w_{L}(l)$. For $l<l_{L}^{u *}, R_{H}^{\prime}(l)-\left(w_{L}(l) l\right)^{\prime}=R_{H}^{\prime}(l)-\left(R_{L}^{\prime}(l)+R_{L}^{\prime \prime}(l)-C^{\prime}(l)\right)>0$, given $R_{H}^{\prime}(l)>R_{L}^{\prime}(l)$, $R_{L}^{\prime \prime}(l) \leq 0$, and $C^{\prime}(l) \geq 0$. For $l \in\left(l_{L}^{u *}, l_{H}^{*}\right), R_{H}^{\prime}(l)-\left(w_{L}(l) l\right)^{\prime}=R_{H}^{\prime}(l)-\left(\bar{w}-C^{\prime}(l)\right)>0$, since for $l<l_{H}^{*}, R_{H}^{\prime}(l)-\left(\bar{w}-C^{\prime}(l)\right) \geq R_{H}^{\prime}(l)-\left(w_{H}(l) l\right)^{\prime}>0$. Therefore, $R_{H}(l)-w_{L}(l) l$ is increasing for $l<l_{H}^{*}$.

Proof of proposition 8. Let $l_{M} \equiv \arg \max _{l} R_{L}(l)-w_{H}(l) l$. Then necessary conditions for the existence of a fully separating equilibrium are:

$$
\begin{array}{r}
R_{H}\left(l_{H}\right)-w_{H}\left(l_{H}\right) l_{H} \geq o\left(w_{L}, l_{L}\right)\left(R_{H}\left(l_{H}^{u}\left(l_{L}\right)\right)-w_{H}^{u}\left(l_{L}\right) l_{H}^{u}\left(l_{L}\right)\right) \\
+\left(1-o\left(w_{L}, l_{L}\right)\right)\left(R_{H}\left(l_{L}\right)-w_{L} l_{L}\right) \\
o\left(w_{L}, l_{L}\right)\left(R_{L}\left(l_{L}^{u}\left(l_{L}\right)\right)-w_{L}^{u}\left(l_{L}\right) l_{L}^{u}\left(l_{L}\right)\right)+\left(1-o\left(w_{L}, l_{L}\right)\right)\left(R_{L}\left(l_{L}\right)-w_{L} l_{L}\right) \geq \\
R_{L}\left(l_{M}\right)-w_{H}\left(l_{M}\right) l_{M} \\
o\left(w_{L}, l_{L}\right)\left(R_{L}\left(l_{L}^{u}\left(l_{L}\right)\right)-w_{L}^{u}\left(l_{L}\right) l_{L}^{u}\left(l_{L}\right)\right)+\left(1-o\left(w_{L}, l_{L}\right)\right)\left(R_{L}\left(l_{L}\right)-w_{L} l_{L}\right) \\
R_{L}\left(l_{L}^{u *}\right)-w_{L}^{u *} l_{L}^{u *}
\end{array}
$$


A condition similar to (9) is not required as it was already shown in proposition 7 that $\mathrm{H}$ prefers no organization.

If $\bar{l}>l_{L}^{*}$ then at any fully separating equilibrium, $\left(w_{L}, l_{L}\right)=\left(w_{L}^{*}, l_{L}^{*}\right)$, and $o\left(w_{L}, l_{L}\right)=0$. To check existence, note that $\bar{l} \geq l_{L}^{*}$ guarantees that (7) holds, and optimality of $l_{L}^{*}$ guarantees that both (8) and (9) hold as well. Lastly, the beliefs $q(w, l)=0$ for $l \leq \bar{l}$, and $q(w, l)=1$ for $l>\bar{l}$ support the equilibrium, and satisfy the Intuitive Criterion. No other $\left(w_{L}, l_{L}\right)$ can be played at an equilibrium that survives the Intuitive Criterion, as this criterion ensures that $q\left(w_{L}^{*}, l_{L}^{*}\right)=0$, so that $\left(w_{L}^{*}, l_{L}^{*}\right)$ would be a profitable deviation for $\mathrm{L}$.

Proof of proposition 9. i. Let $\bar{l} \leq l_{L}^{*}$. First note that it has to be the case that

$$
R_{L}\left(l_{M}\right)-w_{H}\left(l_{M}\right) l_{M} \leq R(\bar{l})-w_{L}(\bar{l}) \bar{l} .
$$

(That is, it is not possible that $\mathrm{H}$ would like to imitate $\mathrm{L}$, and $\mathrm{L}$ would like to imitate $\mathrm{H}$ at the same time). To see this, assume instead that

$$
R_{L}\left(l_{M}\right)-w_{H}\left(l_{M}\right) l_{M}>R_{L}(\bar{l})-w_{L}(\bar{l}) \bar{l}
$$

This implies that $l_{M}>\bar{l}$. Otherwise, by 4 . in lemma 1, and the fact that $w_{L}(l) \leq w_{H}(l)$,

$$
\begin{aligned}
R(\bar{l})-w_{L}(\bar{l}) \bar{l}> & R\left(l_{M}\right)-w_{L}\left(l_{M}\right) l_{M}> \\
& >R\left(l_{M}\right)-w_{H}\left(l_{M}\right) l_{M} .
\end{aligned}
$$

Now, by definition,

$$
R_{H}(\bar{l})-w_{L}(\bar{l}) \bar{l}>R_{H}\left(l_{M}\right)-w_{H}\left(l_{M}\right) l_{M}
$$

so that $w_{L}(\bar{l}) \bar{l}<R_{H}(\bar{l})-\left(R_{H}\left(l_{M}\right)-w_{H}\left(l_{M}\right) l_{M}\right)$, which implies $R_{H}(\bar{l})-\left(R_{H}\left(l_{M}\right)-w_{H}\left(l_{M}\right) l_{M}\right)>$ $R_{L}(\bar{l})-\left(R_{L}\left(l_{M}\right)-w_{H}\left(l_{M}\right) l_{M}\right)$. Or, rearranging $R_{H}(\bar{l})-R_{H}\left(l_{M}\right)>R_{L}(\bar{l})-R_{L}\left(l_{M}\right)$, but this is possible only if $l_{M}<\bar{l}$, which contradicts $l_{M}>\bar{l}$. Therefore (11) cannot hold.

Let

$$
R_{L}(\bar{l})-w_{L}(\bar{l}) \bar{l} \geq R_{L}\left(l_{L}^{u *}\right)-w_{L}^{u *} l_{L}^{u *}
$$

Then, there exist fully separating equilibria that survive the Intuitive Criterion such that $\left(w_{L}, l_{L}\right)=\left(w_{L}(\bar{l}), \bar{l}\right)$, and $o\left(w_{L}(\bar{l}), \bar{l}\right)=0$. To see this note that (7) holds by definition of $\bar{l}$, and (10) guarantees that (8) also holds. The same beliefs as in the previous proof would support the equilibrium. Note that in this case, there exist no other equilibria with zero probability of organization, as any equilibrium with $l_{L}<\bar{l}$ would not survive the Intuitive Criterion, and if $\left(w_{L}, l_{L}\right)=\left(w_{L}(l), l\right)$ for $l>\bar{l},(7)$ would not hold.

ii. Equilibria with positive probability of organization can exist for $l \geq \bar{l}$ (if $l<\bar{l}$ they would not survive the Intuitive Criterion). To see this, notice that if $R_{L}\left(l_{M}\right)-w_{H}\left(l_{M}\right) l_{M}<$ 
$R_{L}(\bar{l})-w_{L}(\bar{l}) \bar{l}$, and $R_{L}\left(l_{L}^{u *}\right)-w_{L}^{u *} l_{L}^{u *}<R_{L}(\bar{l})-w_{L}(\bar{l}) \bar{l}$, then it is possible to find an $l_{L}=\bar{l}+\epsilon$, with $\epsilon>0$, and an $o>0$ such that $\mathrm{H}$ prefers $\left(w_{H}^{*}, l_{H}^{*}\right)$ to $\left(w_{L}\left(l_{L}\right), l_{L}\right)$ if $o\left(w_{L}\left(l_{L}\right), l_{L}\right)=o$, and $\mathrm{L}$ still prefers $\left(w_{L}\left(l_{L}\right), l_{L}\right)$ to imitating $\mathrm{H}$ or becoming organized with certainty. To guarantee that (7) holds, it is enough to set

$$
o=\frac{\left(R_{H}(\bar{l}+\epsilon)-w_{L}(\bar{l}+\epsilon)(\bar{l}+\epsilon)\right)-\left(R_{H}(\bar{l})-w_{L}(\bar{l}) \bar{l}\right)}{\left(R_{H}(\bar{l}+\epsilon)-w_{L}(\bar{l}+\epsilon)(\bar{l}+\epsilon)\right)-\left(R_{H}\left(l_{H}^{u}((\bar{l}+\epsilon))-w_{H}^{u}(\bar{l}+\epsilon) l_{H}^{u}(\bar{l}+\epsilon)\right)\right.}
$$

For $\epsilon$ small enough, (8) and (9) will still hold.

Proof of proposition 10. Let $\left(w_{L}, l_{L}\right)=\left(w_{L}(\bar{l})-t, \bar{l}\right)$, for some $t>0$, and let $q(w, l)=1$ for $l>\bar{l}$, and $q(w, l)=0$ for $l \leq \bar{l}$. These beliefs satisfy the Intuitive Criterion, and, given the beliefs, L firms behave optimally (as it was shown above that if $\bar{l}<l_{L}^{*}, R_{L}(\bar{l})-w_{L}(\bar{l}) \bar{l} \geq$ $\left.R_{L}\left(l_{M}\right)-w_{H}\left(l_{M}\right) l_{M}\right)$.

Note also that no equilibrium exists at which organization is avoided with certainty, as any such equilibrium would require $l_{L}>\bar{l}$, in which case, $\mathrm{H}$ firms would want to imitate $\mathrm{L}$ firms, so that H's incentive compatibility constraint would not hold. There can also exist fully separating equilibria with $o\left(w_{L}, l_{L}\right) \in(0,1)$. Let $\underline{l}<l_{L}^{*}$ be defined by $R_{L}(\underline{l})-w_{L}(\underline{l}) \underline{l}=$ $R_{L}\left(l_{L}^{u *}\right)-w_{L}^{u *} l_{L}^{u *}$, so that $\underline{l}>\bar{l}$, and let $l_{L}=\underline{l}$, and $w_{L}=w_{L}(\underline{l})$. Then, if $o\left(w_{L}, l_{L}\right) \geq$ $\frac{R_{H}(\underline{l})-w_{L}(\underline{l}) \underline{l}-\left(R_{H}\left(l_{H}\right)-w_{H} l_{H}\right)}{R_{H}(\underline{l})-w_{L}(\underline{l}) \underline{l}-\left(R_{H}\left(l_{H}^{u}(\underline{l})\right)-w_{H}^{u}(\underline{l}) l_{H}^{u}(\underline{l})\right)},(7)$ will hold. On the other hand, since $R_{L}(\underline{l})-w_{L}(\underline{l}) \underline{l}=$ $R_{L}\left(l_{L}^{u *}\right)-w_{L}^{u *} l_{L}^{u *}$, L cannot do better by triggering certain organization. Monotonicity, and the facts that $l_{L}^{*}>\underline{l}>\bar{l}$, and $R_{L}(\bar{l})-w_{L}(\bar{l}) \bar{l} \geq R_{L}\left(l_{M}\right)-w_{H}\left(l_{M}\right) l_{M}$ guarantee that (8) also holds. Mixed strategy equilibria are also possible for $l>\underline{l}$. However, these equilibria involve nonmonotonic beliefs, as they require $q\left(w_{L}, l_{L}\right)=0$ and $q\left(w_{L}(l), l\right)>0$ for $l \in\left[\underline{l}, l_{L}\right)$. 


\section{References}

Abowd, J. M. and H. S. Farber (1990). Product market competition, union organizing activity, and employer resistance. NBER Working Paper No. 3353.

Acemoglu, D. (1995). Asymmetric information, bargaining, and employment fluctuations. International Economic Review 36(4), 1003-1024.

Andrews, M. J., D. N. F. Bell, and R. Upward (1998). Union coverage differentials. some estimates for britain using the new earnings survey panel dataset. Oxford Bulletin of Economics and Statistics 60(1), 47-77.

Azariadis, C. (1983). Employment with asymmetric information. Quarterly Journal of Economics $98(\mathrm{~S}), 157-172$.

Blanchflower, D. G. (1997). Changes over time in union relative wage effects in Great Britain and the United States. NBER Working Paper: 6100.

Blanchflower, D. G. and R. B. Freeman (1992). Unionism in the United States and other advanced OECD countries. Industrial Relations 31(1), 56-79.

Booth, A. L. (1995). The Economics of the Trade Union. Cambridge, U.K.: Cambridge University Press.

Bronars, S. G. and D. R. Deere (1993). Union organizing activity, firm growth and the business cycle. American Economic Review 83(1), 203-220.

Bronfenbrenner, K. (1997). The role of union strategies in NLRB certification elections. Industrial and Labor Relations Review 50(2), 195-212.

Cho, I.-K. and D. Kreps (1987). Signaling games and stable equilibria. Quarterly Journal of Economics 102(2), 179-221.

Dickens, W. T. (1986). Wages, employment, and the threat of collective bargaining by workers. NBER Working Paper No. 1856.

Duncan, G. J. and F. P. Stafford (1980). Do union members receive compensating wage differentials? American Economic Review 70(3), 355-371.

Ehrenberg, R. G. and R. S. Smith (1997). Modern Labor Economics. Sixth Ed. Reading, MA: Addison Wesley.

Farber, H. S. (1990). The decline in unionism in the united states: What can be learned from recent experience. Journal of Labor Economics 8(1), S75-S105.

Flanagan, R. J. (1989). Compliance and enforcement decisions under the National Labor Relations Act. Journal of Labor Economics 7(3), 257-280.

Foulkes, F. K. (1980). Personnel Policies In Large Nonunion Companies. Englewood Cliffs, NJ: Prentice Hall Inc. 
Freeman, R. B. (1986). The effect of the union wage differential on management opposition and union organizing success. American Economic Review 76(2), 92-96.

Freeman, R. B. (2000). Single peaked vs. diversified capitalism: The relationship between economic institutions and outcomes. NBER Working Paper No. 7556.

Freeman, R. B. and M. M. Kleiner (1990). Employer behavior in the face of union organizing drives. Industrial and Labor Relations Review 43(4), 351-365.

Freeman, R. B. and J. L. Medoff (1984). What Do Unions Do? New York: Basic Books.

Grossman, S. J. and O. D. Hart (1981). Implicit contracts, moral hazard and unemployment. American Economic Review 71(2), 301-307.

Grossman, S. J. and O. D. Hart (1983). Implicit contracts under asymmetric information. Quarterly Journal of Economics 98(S), 123-156.

Grossman, S. J., O. D. Hart, and E. Maskin (1983). Unemployment with observable aggregate shocks. Journal of Political Economy 91(6), 907-928.

Herz, D. E. (1990). Worker displacement in a period of rapid job expansion: 1983-87. Monthly Labor Review May, 21-33.

Hirsch, B. T. (1991). Labor Unions and the Economic Performance of Firms. Kalamazoo, MI: W.E. Upjohn Institute for Employment Research.

Hirsch, B. T. and E. J. Schumacher (2000). Earnings imputation and bias in wage gap estimates. Mimeo.

Ichniowski, C., R. B. Freeman, and H. Lauer (1989). Collective bargaining laws, threat effects, and the determination of police compensation. Journal of Labor Economics 7(2), 191-209.

Kennan, J. (2000). Informational conflict and business cycles. Mimeo. University of Wisconsin-Madison.

Kennan, J. and R. Wilson (1993). Bargaining with private information. Journal of Economic Literature 31(1), 45-104.

Lazear, E. (1983). A competitive theory of monopoly unionism. American Economic Review 73(4), 631-43.

Lewis, G. H. (1986). Union Relative Wage Effects: a Survey. Chicago, IL: University of Chicago Press.

Linneman, P. and M. L. Wachter (1986). Rising union premiums and the declining boundaries among noncompeting groups. American Economic Review 76(2), 103-108.

Linneman, P., M. L. Wachter, and W. H. Carter (1990). Evaluating the evidence on union employment and wages. Industrial and Labor Relations Review 44(1), 34-53. 
Neumark, D. and M. L. Wachter (1995). Union effects on nonunion wages: Evidence from panel data on industries and cities. Industrial and Labor Relations Review 49(1), 20-38.

Pencavel, J. H. (1991). Labor Markets Under Trade Unionism: Employment, Wages and Hours. Oxford and Cambridge, MA: Basil Blackwell Inc.

Rees, A. and G. P. Schultz (1970). Workers and Wages in an Urban Labor Market. Chicago, IL: University of Chicago Press.

Rosen, S. (1969). Trade union power, threat effects and the extent of organisation. Review of Economic Studies 36(3), 185-96.

Ruback, R. S. and M. B. Zimmerman (1984). Unionization and profitability: Evidence from the capital market. Journal of Political Economy 92(6), 1134-1157.

Ruiz-Verdú, P. (2000). Labor markets under endogenous union formation. Stanford Institute for Economic Policy Research. Discussion Paper No. 00-22.

Segal, I. (1999). Collusion, exclusion and inclusion in random order bargaining. mimeo, Stanford University.

Stewart, M. B. (1991). Union wage differentials in the face of changes in the economic and legal environment. Economica 58(230), 155-72.

Stewart, M. B. (1995). Union wage differentials in an era of declining unionisation. Oxford Bulletin of Economics and Statistics 57(2), 143-66.

Stole, L. and J. Zwiebel (1996). Intra-firm bargaining under non-binding contracts. Review of Economic Studies 63(3), 375-410. 